\title{
Marcadores Geoquímicos como Indicadores de Atributos Culturais na Paisagem Geomorfológica no Parque Nacional Serra da Capivara, Piauí-Brasil
}

\author{
Geochemical Markers as indicators of Cultural Attributes in the \\ Geomorphological landscape in the Serra da Capivara National \\ Park, Piauí-Brazil
}

Beneilde Cabral Moraes, Coordenação de Química, Centro de Ciências da Natureza, Universidade Estadual do Piauí, Brasil, beneilde@gmail.com

(D) https://orcid.org/0000-0003-3642-916X

Liége de Souza Moura, Coordenação de Geografia, Centro de Ciências Humanas e Letras, Universidade Estadual do Piauí, Brasil, liege.moura@hotmail.com

(1) https://orcid.org/0000-0003-0783-473X

Rita de Cássia Pereira Santos Carvalho, Coordenação de Química, Centro de Ciências da Natureza, Universidade Estadual do Piauí, Brasil, ritacpsc@oi.com.br

(1) https://orcid.org/0000-0001-5088-0307

Antonio Carlos de Barros Corrêa, GEQUA, Departamento de Ciências Geográficas, Centro de Filosofia e Ciências Humanas, Universidade Federal de Pernambuco, Brasil, dbiase2001@terra.com.br

(1) https://orcid.org/0000-0001-9578-7501

Resumo: As investigações sobre indícios de ocupação humana pré-histórica, através de análise química elementar tem sido uma importante ferramenta no estudo de sedimentos arqueológicos. Nesta perspectiva, buscou-se aprofundar as investigações acerca dos indícios de tal ocupação através de marcadores geoquímicos nos sítios Toca Sítio do Meio e Toca do Gordo do Garrincho, localizados no Parque Nacional Serra da Capivara-Piauí, Brasil, e em seu entorno. Para tanto, realizou-se um estudo morfoestratigráfico, sedimentológico e geoquímico de depósitos, utilizando métodos físicos, químicos e instrumentais. Os dados obtidos mostraram resultados para a determinação da textura do solo, apontando para diferentes concentrações de argilominerais, influenciando na fixação de fósforo $(P)$ e outros marcadores. O elemento $\mathrm{P}$ está presente em todas as amostras de forma significativa, embora não esteja presente no material parental, indicando que houve um input alóctone, sugerindo um forte indício da existência de níveis de ocupação humana. Deve-se considerar que a associação climática que se faz entre argilominerais e sedimentos deve ser mais cautelosa, pois se observa que há um controle muito grande da rocha. Contudo, foi possível estabelecer parâmetros teórico-metodológicos de indicadores ambientais com aplicação de marcadores geoquímicos para a indicação de níveis de ocupação humana pré-histórica e reconstrução da dinâmica e evolução ambiental de paleopaisagens.

Palavras-chave: Ocupação humana; Marcador químico; Paloambientes; Dinâmica da paisagem.

\begin{abstract}
Investigation about Prehistoric human occupation evidences using elemental chemical analysis have been an important tool in the study of archaeological sediments. In this perspective, we sought to further investigate the evidence of such occupation through geochemical markers in the Toca Sítio do Meio and Toca do Gordo do Garrincho sites, located in the Serra da Capivara-Piauí National Park, Brazil, and its surroundings. Therefore, a morphostratigraphic, sedimentological and geochemical study of deposits was carried out using physical, chemical and instrumental methods. The obtained data showed results for the soil texture determination, pointing to different clay minerals concentrations, influencing the phosphorus (P) fixation and other markers. The "P" element is present in all samples significantly, although it is not present in the parenting stuff, indicating that there was an allochthonous input, suggesting a strong evidence of the existence of human occupation levels. It should be considered that the climatic association between clay minerals and sediments should be taken more carefully, since
\end{abstract}


it is observed that there is a great control of the rock. However, it was possible to establish theoretical and methodological parameters of environmental indicators with the application of geochemical markers for the indication of prehistoric human occupation levels and reconstruction of the dynamics and environmental evolution of Paleolandscapes.

Keywords: Human occupation; Chemical marker; Paleoenvironment; Landscape dynamics.

\section{Introdução}

O complexo sistema de ocupação de áreas por grupos humanos pré-históricos está intrinsecamente relacionado com a paisagem e com as suas componentes fisiográficas e geológicas (Angelucci, de Deus, 2006). A percepção da interdependência entre o sistema natural e o cultural é um dos elementos centrais da geoarqueologia, ramo da arqueologia que permite integrar e analisar, simultaneamente e sob uma perspectiva evolucional, as características geológicas e geomorfológicas no estudo de registros arqueológicos e instalações humanas préhistóricas, como parte componente do ecossistema de um dado território (Suguio, 1998; Angelucci, de Deus, 2006; Angelucci, Zilhão, 2009; Angelucci et al., 2013; Angelucci et al., 2018). As circunstâncias do ambiente em qualquer época refletem não apenas as influências antrópicas, mas também os processos naturais e fenômenos, os quais podem causar mudanças que são independentes da ação humana no decurso da história evolutiva da terra e da biosfera, e essa história tem sido marcada por grandes mudanças ambientais. Sua interface é resultante da interação entre as ciências da terra assim como a Arqueologia, e tem fornecido, desde as teorias arqueológicas mais remotas até as atuais, dados que ajudam a compreender questões referentes à evolução da paisagem.

As relações entre relevo e sistema de assentamentos pré-históricos e os processos formuladores dos sítios arqueológicos são essenciais em todas as fases do desenvolvimento de pesquisas arqueológicas (Santos, 2007). Esses dados têm possibilitado o entendimento e a reconstrução de ambientes que indicam a forma de interação entre os grupos humanos com o contexto paisagístico em que viveram e também podem ser utilizados na elucidação de questões ainda obscuras, dentre as quais, algumas se destacam: como a paisagem se transforma com o decorrer do tempo; como as comunidades humanas do passado exploraram e modificaram os seus territórios; e como se formaram os depósitos arqueológicos (Angelucci, Peresani, 2001; Angelucci et al., 2013).

Essas indagações levam a uma linha de investigação ainda pouco explorada para algumas regiões, contudo determinantes na elucidação de interrogações sobre o processo de ocupação do homem pré-histórico. Para a construção desse conhecimento, utilizam-se métodos de análises que partem do geossistema para direcionar o estudo da paisagem, concepção que possui suas bases enquanto referencial teórico-metodológico na Teoria Geral de Sistemas, e, em especial, aplicada à geomorfologia e à Geografia Física, as quais têm como propósito tratar da totalidade, da interação dinâmica e hierarquicamente organizada. Assim, desenvolve- 
se uma integração e unificação entre as ciências naturais e sociais, por meio da influência mútua e ativa de seus componentes (da Costa Honorato, 2009; Torres et al., 2012).

$\mathrm{Na}$ Arqueologia, o estudo de grupos humanos em uma escala histórica investiga o passado e o homem como ente social, mas não avançaria se não contasse também com a colaboração de outros diversos braços das ciências, dentre elas, a geoquímica. Desse modo, através do estudo geoquímico, busca-se avaliar a natureza e o teor de elementos químicos presentes no solo, sedimentos e em peças, como de cerâmicas, os quais poderão indicar a presença de atividade humana no local onde se desenvolveram as ações e interações entre as populações ancestrais e o ambiente por meio das possíveis alterações promovidas no território, como por exemplo, o uso dos recursos naturais.

A atividade humana provoca mudanças e incrementos nas assinaturas físico-químicas do solo, altera sua concentração, seu processo de agregação molecular e sua composição física, por meio da adição de novas partículas ou pela sua substituição. Portanto, a detalhada investigação do contexto geomorfológico, e da composição dos sedimentos oriundos de diferentes perfis podem fornecer indícios relativos à sua origem, função ou às atividades exercidas no local, que necessariamente modificam o ciclo natural de formação do solo, e provocam uma série de alterações no substrato de ocupação através da adição de diferentes resíduos que, por sua vez, integrados ao substrato poderão induzir um intemperismo diferencial que modifica física e quimicamente o sítio ocupado (Manzanilla, Barba 1994; Wilson et al., 2008; Villagran, Schaefer, 2011; Moraes et al., 2013).

Essas modificações podem ser tão marcadas ao ponto de conduzirem a uma configuração muito diferente da existente no momento da ocupação do sítio. Tais alterações podem ser detectadas através do emprego de métodos analíticos e instrumentais que identifiquem as concentrações de determinados elementos chave (Villagran, Schaefer, 2011), marcadores, especialmente o fósforo (P). Esse elemento, sob a forma de fosfatos $\left(\mathrm{PO}_{4}^{-3}\right)$, tem demonstrado ser apropriado na caracterização de solos e sedimentos afetados pela ação humana. A quantidade total de partículas de fosfato, especialmente associadas ao Cálcio (Ca), Ferro (Fe) e ao Alumínio (Al) denuncia, em grande parte, as atividades humanas que ali se processaram. As diferentes vias pelas quais as pessoas podem adicionar fosfato a um solo ou sedimento incluem a deposição ou queima de materiais orgânicos e inorgânicos (restos animais e plantas e de subprodutos metabólicos como dejetos ou urina). A entrada do fósforo no solo ou sedimento pode ser tanto na forma de fosfato orgânico como inorgânico e tem a particularidade de persistir no tempo por causa da sua forte fixação, precipitação, baixa solubilidade, oxidação e baixa mobilidade. Em suma, o homem rompe com o ciclo natural do fosfato e o transforma em um indicador de suas ações sobre o meio (Proudfoot, 1976; Eidt, 1977; Parnell et al., 2002; Holliday, 2004; Moraes, 2004; Lage et al., 2007; Villagran, 2010). 
Neste contexto, este estudo teve como propósito aprofundar estudos sobre indícios de ocupação humana pré-histórica através da caracterização geoquímica de sedimentos e sua extrapolação para outras áreas geomorfologicamente similares, cujos sedimentos não tenham ainda sido estudados em sítios do Parque Nacional Serra da Capivara-PI e seu entorno, no sentido de fornecer dados que contribuam para a compreensão do processo de ocupação humana pré-histórica nessa região.

A escolha do tema relacionado ao processo de ocupação humana em interface com a dinâmica da paisagem, constituição antrópico-natural, decorre, especialmente, da grande riqueza arqueológica existente em todo o território piauiense, marcado pela presença do homem pré-histórico, que pode ser visualizado pelos milhares de sítios arqueológicos distribuídos em toda a extensão territorial do estado, sendo que a maioria deles caracterizada pela arte rupestre, embora também sejam encontrados sítios históricos, aldeias de agricultores, ceramistas, oficinas líticas, sítios paleontológicos e com enterramentos. Além disso, contribui também para a reafirmação e/ou complementação de pesquisas já existentes na região, estimulando estudos do patrimônio geomorfológico e o geoturismo no Piauí, com vistas a servir como modelo interpretativo na formulação de hipóteses sobre o processo de ocupação humana pré-histórica no continente americano, bem como fomentar o debate dessa questão através de novos olhares, com argumentos para romper com o ceticismo ainda existente em relação às cronologias obtidas para a penetração humana na América do Sul.

Desse modo, objetivou-se aprofundar as investigações sobre indícios de ocupação humana pré-histórica através da caracterização geoarqueológica e geoquímica de sedimentos, estabelecendo-se um método de análise com base na sua aplicação nos sítios Toca do Sítio do Meio e Toca do Gordo do Garrincho, do Parque Nacional Serra da Capivara - PI e seu entorno.

\section{Enquadramento}

\section{1. Área de Estudo e Contexto Arqueológico}

A crescente expansão da pré-história do continente americano está sendo construída graças às inúmeras pesquisas como as desenvolvidas no Parque Nacional Serra da Capivara (PNSC). O estado do Piauí encontra-se marcado pela presença do homem americano em milhares de sítios arqueológicos distribuídos em todo o seu território, podendo ser visualizado através de vestígios de uma abundante cultura e de um ambiente outrora propício para a ocupação humana com base na oferta de recursos naturais disponíveis, em uma dinâmica holística e não fragmentada, na qual todos os elementos se relacionam e sofrem interferências dessa relação, em uma dinamicidade, que integra todo o sistema sob um fluxo contínuo de entrada e saída de matéria e energia (da Costa Honorato, 2009; Lage et al., 2007).

O Parque Nacional Serra da Capivara, compreende áreas dos municípios de Brejo do Piauí, João Costa, São Raimundo Nonato e Coronel José Dias, sendo a cidade de 
São Raimundo Nonato o maior centro urbano mais próximo ao parque, localizada a aproximadamente $524 \mathrm{~km}$ da capital, Teresina.

O PNSC foi criando em 1979, compreende uma área ambiental de rara beleza, na qual se encontra uma das maiores concentrações de sítios pré-históricos das Américas, inúmeros sítios característicos de arte rupestre, históricos, de oficinas líticas, sítios paleontológicos, com enterramentos e de ceramistas, justificando seu interesse científico e potencial turístico cultural e ecológico para a região. Encontrase coberto pela vegetação de caatinga, inserido nos limites ocidentais deste bioma, na faixa de transição para o bioma do cerrado. A área é fruto de uma história geológica, climática e biológica complexa. Sua diversidade de vida presente atualmente só foi possível graças à variabilidade do relevo e aos múltiplos habitats modelados, ao longo de milhares de anos, pelos processos superficiais.

As coordenadas geográficas do Parque, $8^{\circ} 26^{\prime} 50^{\prime \prime}$ e $8^{\circ} 54^{\prime} 23^{\prime \prime}$ de latitude Sul e 42 $12^{\circ}$ $57^{\prime \prime}$ e $42^{\circ} 45^{\prime} 21^{\prime \prime}$ de longitude Oeste, delimitam uma área de 129.593 hectares e perímetro de $214,235 \mathrm{Km}$ (Figura 1). Em seu entorno, foram instituídas áreas de preservação permanente (APP), que constituem uma faixa suplementar para o desenvolvimento de pesquisas e ações de extensão, onde ainda se encontram sítios arqueológicos, como por exemplo, o sítio "Toca do Gordo do Garrincho" que faz parte desse estudo.

O Parque Nacional Serra da Capivara foi considerado pela UNESCO como Patrimônio Cultural da Humanidade em 1991, por apresentar um grande número de sítios arqueológicos que servem de testemunho da presença do homem pré-histórico. Até o momento, mais de 1.200 sítios foram cadastrados, dos quais pelo menos 1000 conservam nas paredes rochosas vestígios de arte rupestre, grafismos de grande relevância cultural e científica.

As pinturas e gravuras rupestres, registradas nas paredes e tetos de abrigos e em blocos rochosos destacam-se, entre outras, pela estética e interpretação de diferentes grupos humanos que ali deixaram suas marcas, demonstrando suas ações, afazeres, condutas e rituais. Estudos já realizados sobre os pigmentos de pinturas rupestres indicam sua origem de precursores naturais. As cores eram obtidas a partir de ocres ricos em óxidos de ferro (hematita, $\alpha \mathrm{Fe}_{2} \mathrm{O}_{3}$, e goethita, $\alpha \mathrm{FeOOH}$ ), carvão vegetal, ossos queimados e óxido de manganês $\left(\mathrm{MnO}_{2}\right)$, entre outros minerais. É factível também que tenham sido feitas pinturas à base de pigmentos vegetais, que podem ter desaparecido totalmente no decorrer do tempo (Lage, 1996; Guidon, et al. 2002; Moraes, 2003; Alves et al., 2011; Cavalcante, 2009). 


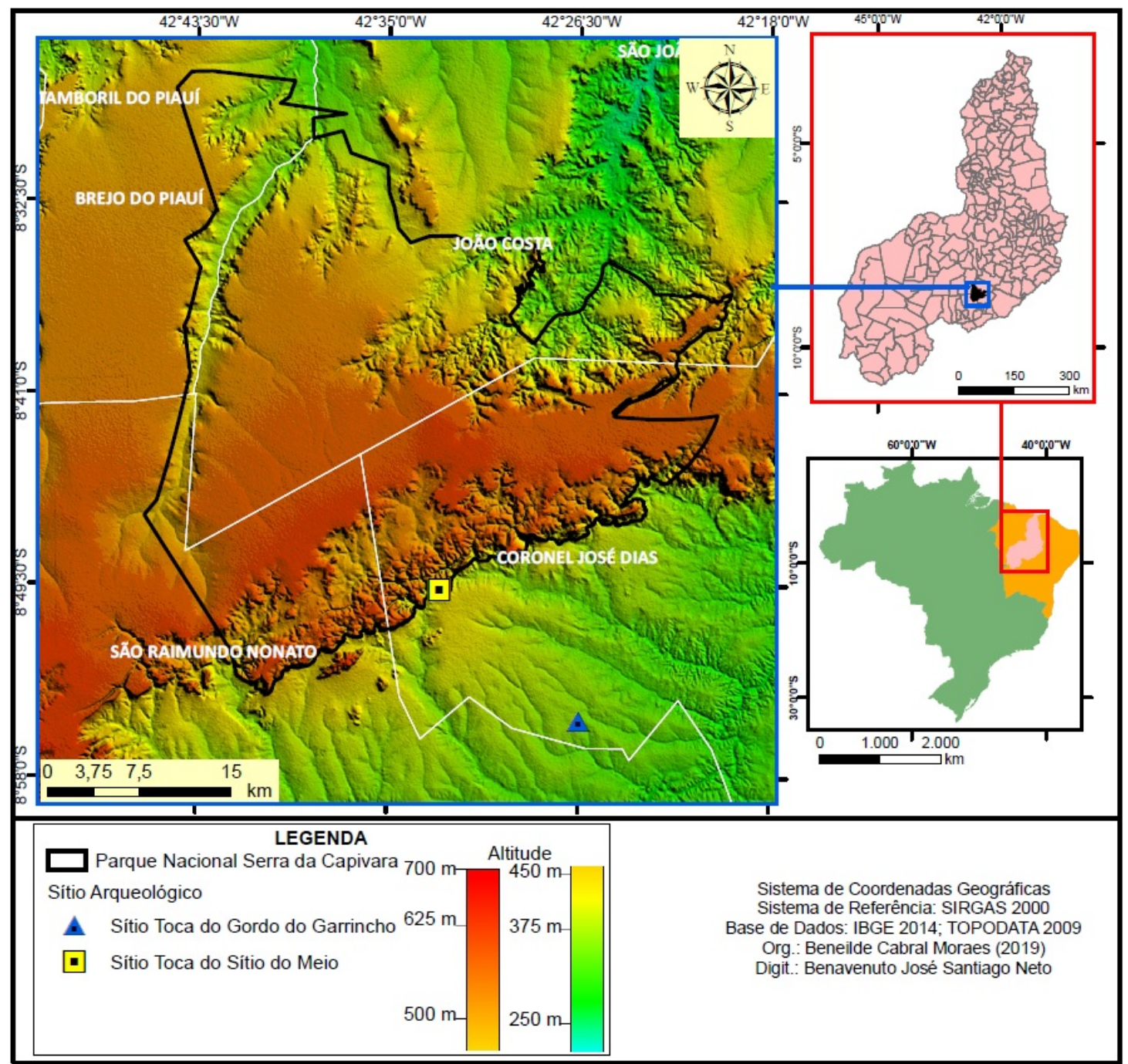

Figura 1: Mapa de localização do Parque Nacional Serra da Capivara, Piauí-Brasil e dos Sítios estudados.

O Parque Nacional Serra da Capivara, além das pinturas rupestres com seus pigmentos, é também reconhecido por seus inúmeros vestígios materiais, como: fragmentos de carvão, instrumentos líticos, sementes, vestígios ósseos humanos e de animais pré-históricos, fragmentos de cerâmica e fogueiras estruturadas, como as que foram evidenciadas no sítio Boqueirão da Pedra Furada, com datações que chegam há pelo menos 50.000 anos, marcas que dizem respeito aos registros mais antigos da presença do homem no continente americano (Parenti, 1993; Felice, 2006).

\subsection{Descrição dos Sítios}

A escolha dos sítios, objeto deste estudo, o Sítio Toca do Gordo do Garrincho, localizado no entorno do PNSC e o sítio Toca do Sítio do Meio localizado dentro do PNSC, se deu por sua relevância arqueológica e geomorfológica. Do ponto de vista arqueológico, neles foram encontrados vestígios significativos de ocupação humana, dentre os quais, cita-se: pinturas rupestres, material lítico, fragmentos de crânio e dentes humanos, ossos da megafauna, de oficina lítica, carvão, sepultamento humano, etc. Quanto ao ponto de vista geomorfológico, estes sítios foram escolhidos 
por estarem localizados em domínios morfoestruturais distintos: a Depressão Periférica do São Francisco, sob o embasamento cristalino, e a Bacia sedimentar do Parnaíba.

A aplicação de um método estratigráfico na identificação de marcadores geoquímicos, na análise de perfis arqueológicos desses sítios permite avaliar o processo de desenvolvimento da ocupação da área, suas mudanças ao longo do tempo, bem como compreender sua relação com a evolução dos sistemas naturais do Pleistoceno/ Holoceno.

\section{- Sítio Toca do Sítio do Meio}

Esse sítio foi localizado (coordenada de longitude $42^{\circ} 32^{\prime} 50^{\prime \prime}$ e latitude $8^{\circ} 49^{\prime} 30^{\prime \prime}$ ) no ano de 1973, durante o primeiro levantamento de sítios da região. É um abrigo sob rocha situado no front da cuesta, localmente conhecida como Serra Talhada, portanto na borda sudeste da bacia sedimentar Parnaíba. Essa Serra é trabalhada pela erosão, formando um relevo ruiniforme. Na formação do abrigo, as camadas de arenito são intercaladas por espessas lentes de siltito. Como característica, apresenta grandes blocos de arenito e siltito desprendidos do teto, em suas paredes possuem um grande número de registros de arte rupestre da tradição nordeste, como também em seus blocos desprendidos. Em uma das extremidades do abrigo existe um forno de farinha que foi utilizado por uma família que na região plantava mandioca há mais de 35 anos atrás (Figura 2 e 3) (Melo, 2000).

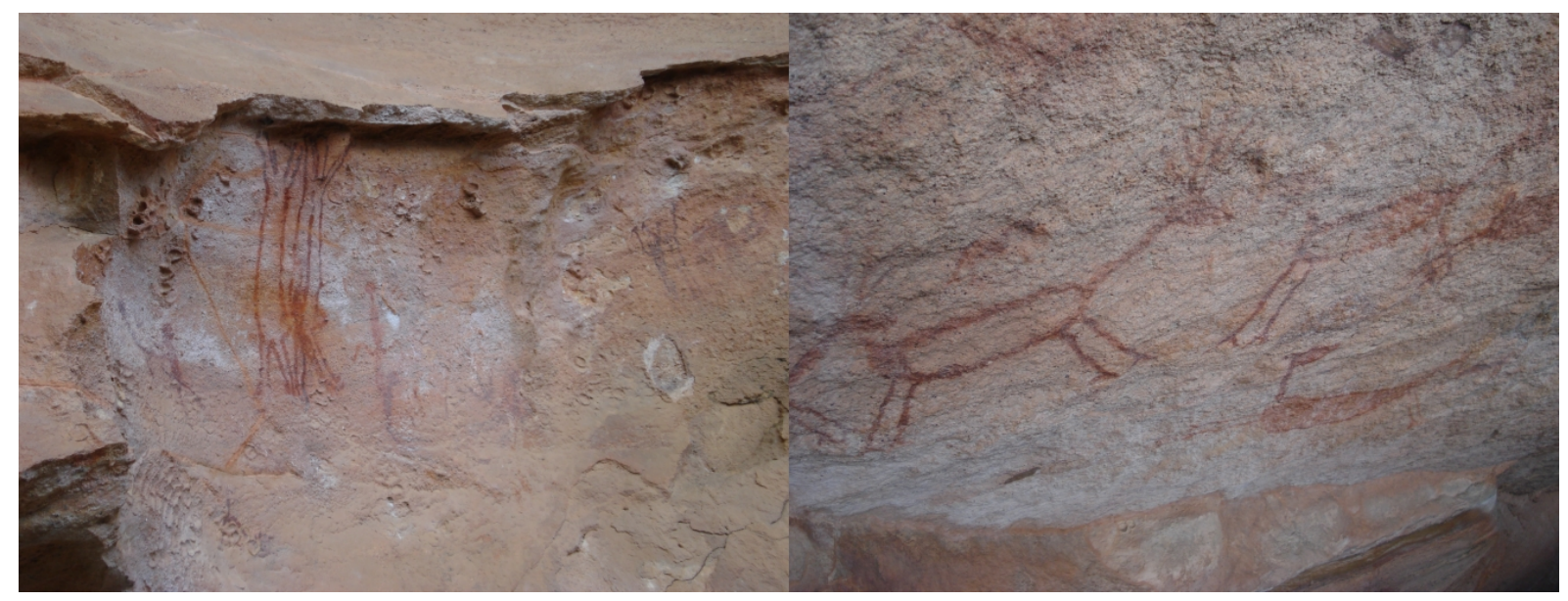

Figura 2: A e B - Pinturas rupestres da Tradição Nordeste nas paredes rochosas do abrigo.

Fonte: Arquivo pessoal (2014).

A Toca do Sítio do Meio teve suas escavações iniciadas em 1978 e concluídas em 2000 (1978/1980, 1991/1992, 1993, 1999 e 2000). Alguns vestígios provenientes dessas escavações apresentaram uma cronologia radiocarbônica que vai de 8.960 anos AP (Antes do Presente) até 20.280 anos AP. Sua indústria lítica é composta de numerosas lascas trabalhadas, vários tipos de raspadores, chopper e lesmas. Outros vestígios extremamente importantes foram evidenciados nessas escavações entre eles estão: dois fragmentos cerâmicos, cujo carvão, em contato diretamente associado, foi datado de 8.960 anos AP; e uma lâmina de machado polido em 
granodiorito com encabamento central e finamente trabalhado foi encontrada na base de uma fogueira, e o carvão, em contato direto com o machado, apresentou a idade de 9.200 anos AP (Melo, 2000; Santos 2007). No ano de 2000, com a retomada das escavações, foi possível ainda encontrar várias estruturas de combustão formadas especialmente por blocos de arenito. Os carvões componentes dessas fogueiras foram datados por ${ }^{14} \mathrm{C}$ em $8.805 \pm 50$ anos AP (Pinheiro, Melo, 2005 apud Santos 2007).

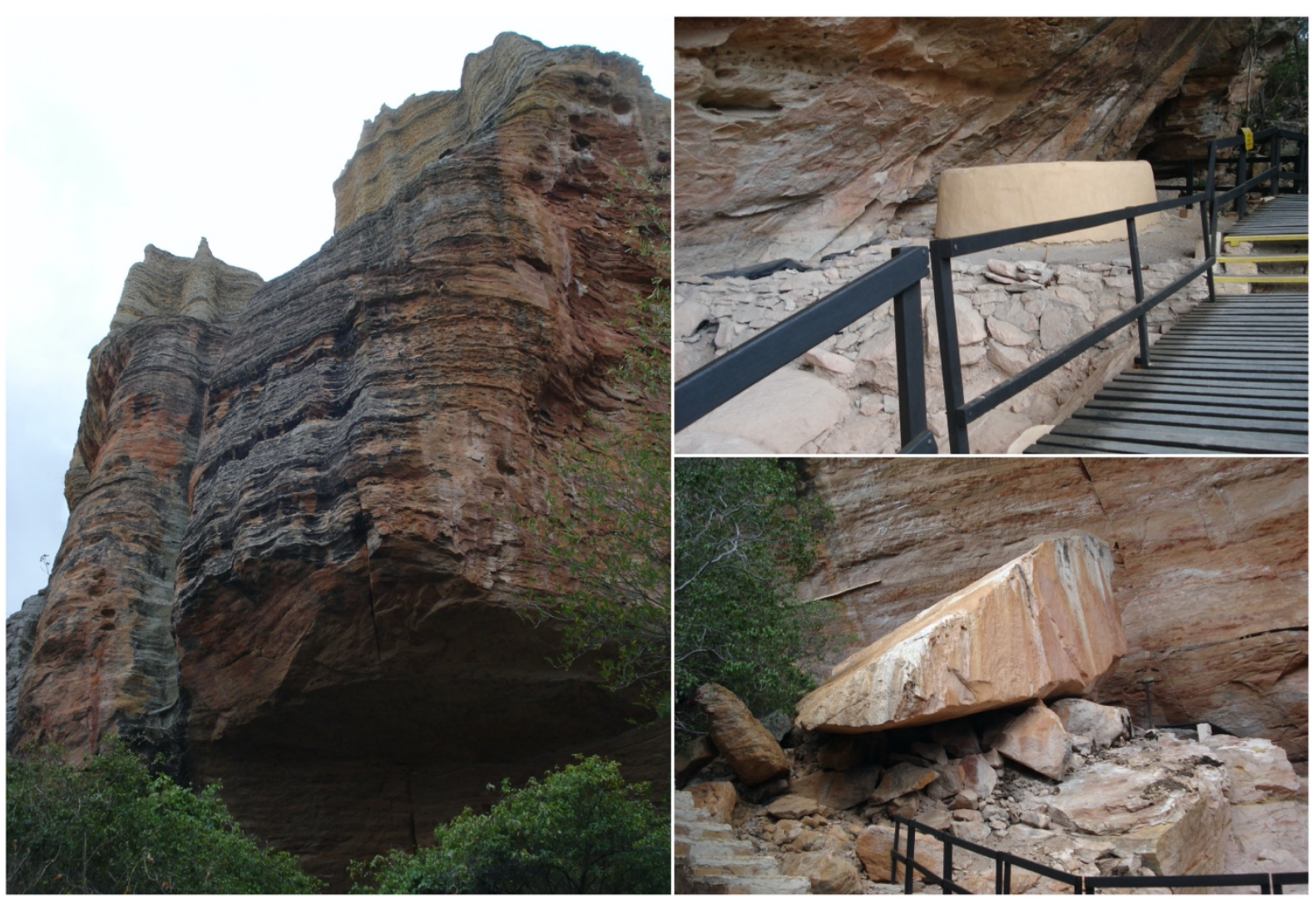

Figura 3: A - Abrigo trabalhado pela erosão; B - Forno de farinha construído no sítio por família de agricultores da região há pelo menos 35 anos; $\mathrm{C}$ - Grandes blocos de arenito desprendidos do teto.

Fonte: Arquivo pessoal (2014).

\section{- Toca do Gordo do Garrincho}

O sítio do Garrincho situa-se na área de preservação permanente (APP), no entorno do Parque Nacional Serra da Capivara (coordenadas geográficas $8^{\circ} 55^{\prime} 51^{\prime \prime} \mathrm{S}$ e $42^{\circ}$ 36 ' 52" W) a $13 \mathrm{Km}$ da cidade de são Raimundo Nonato, às margens da BR 020, no Morro do Garrincho. Esse morro é um afloramento de calcário metamorfizado do Paleozoíco antigo, com abrigos e cavernas, que se sobressaem na planície précambriana da depressão periférica do São Francisco. Os sítios encontrados nos maciços calcários são fossilíferos e apresenta abundante e variada fauna do pleistoceno (Figura 4) (Guérin, 1991), que aparecem associados a vestígios antrópicos, como: fogueiras estruturadas, artefatos líticos e restos ósseos de esqueleto humano. 
Esse sítio foi descoberto em 1981, mas apenas em 1986 foi realizada sua primeira prospecção. Em uma escavação sistemática realizada dentro da caverna durante os anos de 1991 e 1992, foram encontrados dois importantes vestígios que reforçam a ocupação humana nesse sítio, dos quais se dispõe dois dentes humanos associados aos fósseis de mamíferos pleistocênicos sob o manto estalagmítico, datado em 12.170 $\pm 40 \mathrm{AP}$, e fragmentos cranianos, fronto-parietal correspondente a um Homo sapiens arcaico (Peyre, 1993; Guidon et al., 2000; Santos, 2007).

Novas descobertas em escavações de 2003 realizadas por G. D. Felice, permitiram a descoberta de dois novos fósseis, nomeadamente restos cranianos e odontológicos com datações preliminares de 14 - 24 Ka AP, que fazem supor tratar de grande antiguidade, corroborando com a cronologia do sítio do Boqueirão da Pedra Furada, importante referência da antiguidade da ocupação humana da América. Na parte externa do maciço foram conduzidas durante os anos de 2004 e 2005 outras escavações que possibilitaram também mais recentes descobertas. Essas trincheiras revelaram que a ocupação humana e a presença de ossos de megafauna encontrados articulados, se deram em camadas distintas (Felice, 2006).

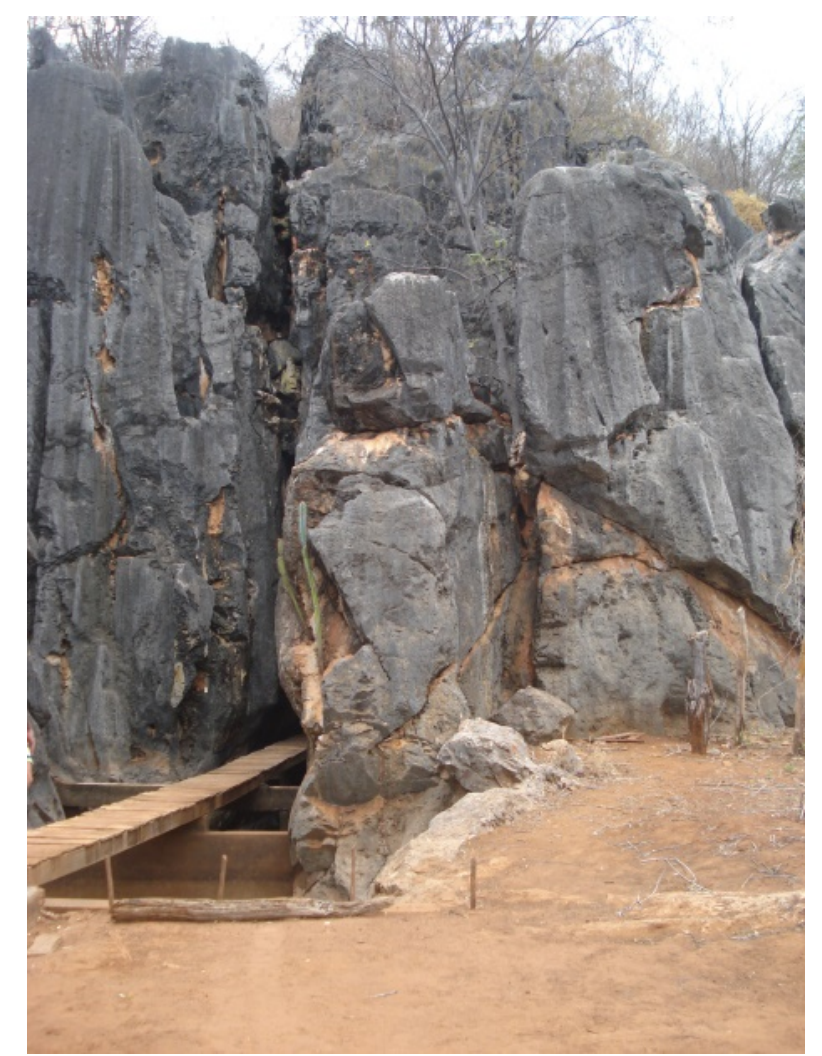

Figura 4: Maciço calcário, Sítio Toca do Gordo do Garrincho, entrada da gruta.

Fonte: Arquivo pessoal (2014).

A descoberta do sítio Toca do Gordo do Garrincho com suas atividades de prospecção e escavações caracterizaram-no como um marco referencial arqueológico, paleontológico e ambiental de grande contribuição para a compreensão das modificações da paisagem e adaptações humanas de ocupação. 


\subsection{Aspectos Geológico e Geomorfológico.}

Quanto ao relevo do Parque Nacional Serra da Capivara pode-se dizer que este congrega um dos mais expressivos conjuntos de relevos ruiniformes sobre arenito do Brasil (Mutzenberg et al., 2015) e apresenta sítios geológicos de grande relevância no contexto da evolução geológica e tectônica da Bacia do Parnaíba.

A história geológica da Bacia nos permite reconstruir os aspectos da paisagem contemporânea. Assim, optamos por elencar alguns eventos fundamentais de sua evolução, a começar com a elevação do nível dos mares, no siluriano-devoniano, cobrindo toda a região, e posterior processo de soerguimento no período Triássico. A partir da reativação geral da área, mediante os controles geológicos em operação a partir do mesozoico, a região passou a ser morfologicamente caracterizada pelo soerguimento da serra, com predomínio da exposição de arenitos e conglomerados, reflexo dos movimentos tectônicos relacionados à abertura do Atlântico Sul. Nos períodos subsequentes, as rochas soerguidas expostas à ação dos agentes erosivos foram esculpidas, resultando nas formas de relevo atuais da paisagem, como os planaltos, boqueirões, serras, morros, serrotes e planícies (CPRM, 2009).

Nessa paisagem, as peculiaridades do terreno estão representadas de forma mais atual pelas chapadas, lateritas, vales internos, cuestas, canyons e desfiladeiros em relevos ruiniformes com esculturas naturais de raríssima beleza e geologicamente associadas ao predomínio de rochas sedimentares - arenitos e conglomerados -, além dos inselbergs ou testemunhos de formações rochosas mais resistentes, que em conjunto constituem as formas mais peculiares de relevo da Bacia do Parnaíba na região, como mostram as imagens representadas na figura 5 (Felice, 2006; CPRM, 2009).

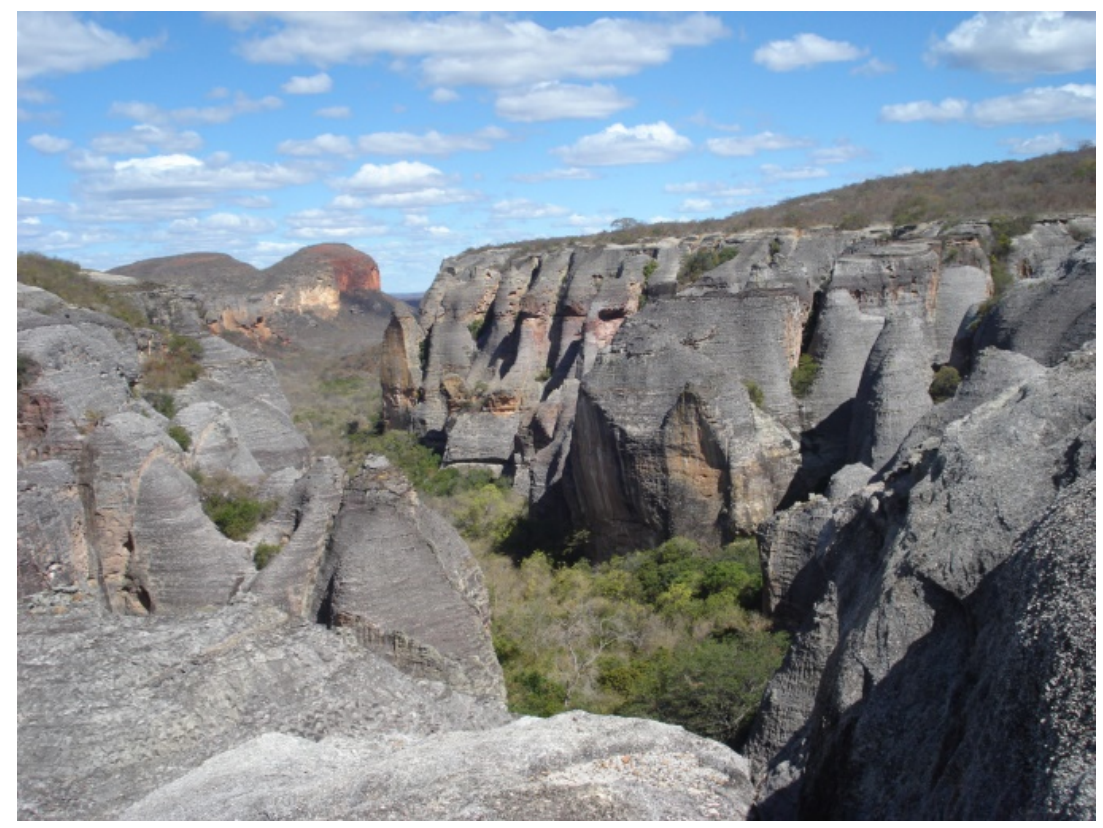

Figura 5: Canyon do Baixão das Andorinhas, formado no arenito pela erosão hídrica.

Fonte: Arquivo pessoal (2014). 
A região em que o PNSC está inserido, apresenta uma área geológica de contato compreendida entre três províncias estruturais do Brasil: a Província do São Francisco, a Província Borborema e a Província do Parnaíba. A parte sul do Parque está presente na província do São Francisco, a mais antiga das três, e é formada por um cráton arqueano que compõe a parte do embasamento da Plataforma Sulamericana (Arruda, 1993; Trompette et al., 1992; Mutzenberg et al., 2015). A Província do São Francisco apresenta rochas metamórficas regionais de alto grau, gnaisses e migmatitos, formando colinas alongadas sobre eixos de dobras de direção geral NorteSul.

A Província da Borborema é caracterizada por um complexo mosaico de áreas dobradas a partir de eventos tectônicos, magmáticos e termais do Ciclo Brasiliano (Almeida et al., 1977). Segundo Mutzenberg et al. (2015), sua história remonta ao arqueano, quando seu embasamento sofreu as deformações iniciais oriundas do Ciclo Orogenético Transamazônico do Paleoproterozóico, para posterior transformação originária do Ciclo Orogenético Brasiliano do Neoproterozóico, resultando na formação de zonas de cisalhamento e falhas transcorrentes de direção E-W e NESW. No conjunto do Parque, a província da Borborema corresponde ao setor extremo sudoeste ao sul do lineamento Pernambuco, que marca o limite da Faixa de Dobramentos do Riacho do Pontal. Esta se estende sobre o Cráton do São Francisco ao Sul, e na porção ocidental é sotoposta pelos depósitos da Bacia intracratônica do Parnaíba (Mutzenberg, 2015).

A Província Sedimentar do Meio Norte (Goes \& Feijó, 1994) compreende quatro sítios deposicionais superpostos, separados por grandes discordâncias estratigráficas, que separam as sequências litológicas da Bacia do Parnaíba. Consiste numa estrutura predominantemente arenítica com altimetria média de $600 \mathrm{~m}$, ocupando uma área de aproximadamente $600.000 \mathrm{~km}^{2}$, em parte dos Estados do Pará, Tocantins, Maranhão, Piauí e Bahia (Santos, 2007). Essa bacia possui contorno circular ou elíptico com perfil simétrico e baixa taxa de subsidência. A sinéclise do Parnaíba é uma bacia de grande dimensão que abriga um pacote de $3000 \mathrm{~m}$ de espessura máxima de sedimentos. Embora essa bacia seja paleozóica, existem depósitos mesozoicos que ocupam grandes áreas.

Na área do Parque, a Bacia do Parnaíba apresenta uma estratigrafia composta de sedimentos clásticos de idades Siluriana e Devoniana, localmente intemperizados, que constituem as suas litologias, representadas pelos Grupos Serra Grande (Siluriano) e Canindé (Devoniano) (Goes \& Feijó, 1994).

\section{Pressupostos Teóricos para o Estudo Geoarqueológico: Arqueologia, Paleoambientes, Estudo do Quaternário e Geoquímica.}

A geoarqueologia utiliza-se principalmente dos princípios e técnicas das ciências naturais, exatas e da terra, integrados dentro da pesquisa arqueológica e em consonância com seus objetivos. Essa interação entre diferentes domínios científicos muito tem contribuído para o desenvolvimento dessa área do conhecimento e na sua constante transformação e evolução como ciência do registro arqueológico. Dessa 
forma, os primeiros passos das Ciências da Terra e da Arqueologia foram comuns e o intercâmbio, conceitual e metodológico, tem sido contínuo e recíproco na história das duas fontes de conhecimento (Angelucci, 2010).

As questões que levam a uma investigação arqueológica recolhem a maior parte dos seus dados da superfície terrestre, ou seja, dos sedimentos superficiais e do solo. Qualquer tipo de espólio arqueológico encontra-se assim intimamente ligado às componentes físicas da paisagem, como são, por exemplo, o relevo ou a organização estratigráfica dos depósitos. Por essa razão as contribuições das Ciências da Terra, como a paleontologia, a estratigrafia ou a geomorfologia têm sido determinantes em todas as fases de desenvolvimento de pesquisas da Arqueologia, e sua investigação inclui uma ou outra componente da geoarqueologia (Angelucci, 2010). De forma ainda mais eficaz com o uso de conhecimentos da física e química no estudo de materiais arqueológicos, a Arqueometria, vem sendo possível montar um quebra-cabeça capaz de explicar a aventura do homem americano na região do Parque Nacional na Serra da Capivara-PI, Brasil, utilizando técnicas analíticas na identificação de marcadores geoquímicos, indicadores de atributos culturais na paisagem geomorfológica da região.

A química de solos e sedimentos arqueológicos tem o potencial de fornecer evidências muito fortes de atividade humana passada em sítios antigos. Atualmente já é bem conhecido que assinaturas químicas de uso de terras antigas podem ser preservadas em solos e sedimentos no decorrer de longos períodos de tempo em uma variedade de ambientes incluindo lagos, cavernas, planícies alagadas, terras encharcadas e solos, de modo que a análise de paleossolos e perfis de solo intacto tem permitido aos pesquisadores distinguirem claramente o nível de enriquecimento antropogênico (Cavalcante et al., 2010; Moraes, 2004).

Segundo Baggio Filho et al., (2012), investigando-se geologicamente, o estudo da composição química dos solos permite obter informações sobre as características da área de origem ou das rochas-fonte e das condições químicas intempéricas, climáticas e tectônicas dominantes. Consequentemente, $\mathrm{o}$ entendimento de solo e geomorfologia na complexidade de suas relações com os comportamentos químicos, físicos e biológicos, tendo em vista uma escala evolutiva de processos intempéricos e da paisagem de forma lógica, torna-se um desafio para codificar a dinâmica do ambiente, mas efetivamente positivo para essa elucidação (Farias, 2012).

A maioria dos compostos químicos intrínsecos ao solo é permanente e pode ser detectado milhares de anos depois de sua formação e compõe parte dos sedimentos, o que torna a análise fosfática um método alternativo e complementar ao estudo arqueológico. Diversas pesquisas de geoarqueologia e geoquímica têm abordado a utilização do fósforo como marcador de atividade humana pré-histórica (Schlezinger e Howes, 2000; Moraes, 2004; Shahack-Gross et al., 2004; Marwick, 2005; Beach et al., 2006; Cavalcante et al., 2010).

Segundo Carter e Sokoloff (1952) concentrações de P (Fósforo), N (Nitrogênio), Ca (Cálcio), Cu (Cobre), Zn (Zinco), Ag (Prata), Mn (Manganês), entre outros, presentes 
no interior ou no entorno de um sítio arqueológico, podem ser interpretados como locais onde o lixo era depositado. Outros elementos como Al (Alumínio), Fe (Ferro), K (Potássio), Sr (Estrôncio), Si (Silício), Na (Sódio), S (Enxofre), Cl (Cloro), Co (Cobalto) e Mg (Magnésio), H (Hidrogênio) são também relevantes para a análise química de sedimentos. Os elementos Al, Fe, H e Ca são importantes para a determinação de pH do solo, sua acidez pode contribuir para a conservação e/ou degradação de vestígios arqueológicos.

Relacionados com atividades agrícolas, onde existem relatos de cultivo, o $\mathrm{P}, \mathrm{Ca}, \mathrm{Sr} \mathrm{e}$ Zn estão especialmente vinculados à ação antrópica que deu origem ao sedimento arqueológico, como também à presença do $C$ (Carbono) na forma de matéria orgânica. Dessa forma, vê-se que o estudo de paleosedimentos pode ser perfeitamente aplicável e pode auxiliar na determinação de áreas de maior atividade humana pré-histórica ou mesmo explicar a sua ausência (Cavalcante et al., 2010; Moraes, 2004).

\section{Metodologia}

A metodologia aplicada para o esclarecimento de questões levantadas nesta investigação foi realizada de forma empírica por meio de trabalho de campo e análise laboratorial. Os métodos e técnicas aqui dispostos representam uma adaptação de análises aplicadas à morfoestratigrafia e sedimentologia, que têm por objeto o estudo dos processos de formação, culturais e naturais, em depósitos arqueológicos estratigráficos (Villagran, 2010).

No trabalho de campo inicialmente obteve-se as imagens e realizou-se a descrição dos sítios Toca do sítio do Meio (SM) e Toca do Gordo do Garrincho (STGG). Posteriormente foram coletadas 14 amostras, 7 amostras do sítio SM e 7 amostras do sítio STGG. Para a análise laboratorial optou-se por testes físicos (sedimentação física, granulometria), testes químicos e instrumentais (análise composicional) a partir da caracterização elementar por Fluorescência de raio $X$ (FRX), mineralógica por Difração de raio $X$ (DRX), Espectroscopia de Absorção Molecular no Ultravioleta/Visível (UV-vis) e Infravermelho com Transformada de Fourier (FTIR) e testes físico-químicos por via úmida, a fim de dosar os teores elementares e construir um quadro geoquímico metodológico descritivo sobre o estudo de solos e sedimentos arqueológicos.

\section{Resultados}

A verificação dos depósitos sedimentares dos sítios estudados do Parque Nacional Serra da Capivara e entorno (Toca do Sítio do Meio e Toca do Gordo do Garrincho), possibilitou a descrição evolutiva da dinâmica ambiental da área, como resultado da combinação de fatores fundamentais: litologia, clima, fatores tectônicos e influência antrópica.

O estudo da topografia, arranjo estrutural, formações superficiais, sedimentos e materiais arqueológicos, permitiu a realização de uma análise sedimentológica dos modelados agradacionais de dois domínios morfoestruturais distintos, a depressão 
periférica do São Francisco ao Sul, com altitude na ordem de $450 \mathrm{~m}$, e, ao Norte, o domínio onde se encontra a Bacia Sedimentar do Parnaíba, com altitudes que variam entre 500 a $600 \mathrm{~m}$.

Pôde-se caracterizar a depressão periférica do São Francisco como uma vasta superfície erosiva plana, pediplano, com projeções de inselbergues, gnáissicos e quartzíticos, batólitos graníticos intrusivos, micaxistos bem aplainados, além de maciços calcários metamorfizados. Para a Bacia Sedimentar do Parnaíba, observase um relevo de extensa superfície plana, que geralmente termina em escarpas abruptas, o front da cuesta da bacia sedimentar do Parnaíba. Esse front apresenta um aspecto ruiniforme devido à sua estrutura diaclasada, formando boqueirões, torres e arcos. Nesses boqueirões, ocorre a maior concentração de sítios arqueológicos com vestígios de pinturas rupestres da região. A borda da bacia foi submetida a longos períodos de denudação marginal, provocando a formação de escarpas voltadas para o exterior e com posição elevada em relação às superfícies de erosão adjacentes, talhadas nas rochas cristalinas pré-cambrianas.

$\mathrm{Na}$ área da bacia sedimentar, o sítio Toca do Sítio do Meio situa-se no sopé do front da cuesta, em um surplomb encaixado sob o paredão rochoso, em uma área de interseção dos planos de estratificação com as estruturas verticais e subverticais das diaclases e fraturas que margeiam a escarpa da cuesta. Os sedimentos quaternários desse sítio se acumulam entre espaços de acomodação ora verticais, ora horizontais, refletindo a adequação do fluxo de baixa ou média viscosidade às rugosidades originais do terreno.

Sítio arqueológico e paleontológico do carste, da região de São Raimundo Nonato, o sítio Toca do Gordo do Garincho representa um conjunto de maciços calcários carstificados bastante diversificados no qual a ação dos processos cársicos desencadeou a formação de espaços de acomodação em amplos recessos erosivos e de dissolução, formando grandes cavidades e até pequenas cavernas. A relevância destas cavidades reside no fato de preservarem importantes testemunhos da evolução geomorfológica da região, como também elementos da paleofauna pleistocênicia e vestígios do homem pré-histórico.

Nesse sítio, os depósitos sedimentares podem ter diferentes origens: de um lado, a sedimentação canalizada por ravinas e sulcos esculpidos pelo processo de dissolução do calcário, com enterramento rápido de animais que morreram sobre o lugar ou vieram com as correntes de água, o que é evidenciado pelos vários esqueletos completos ou fragmentado em conexão anatômica; de outro lado, os preenchimentos em regime de alta energia não canalizados, realizados na superfície e também por entre os recessos da circulação cárstica, comprovados pelos ossos misturados aos seixos de rochas alóctones (Guérin, 1993; Salvia, 2006).

\subsection{Descrição e Análise dos Perfis Estratigráficos}

$\mathrm{Na}$ análise sedimentológica física foram selecionados dois perfis estratigráficos, os quais apresentaram distribuição espacial de modo a contemplar o maior número de 
contextos deposicionais associados aos megacompartimentos de relevo estrutural da área e às duas classes litológicas predominantes de embasamento.

\section{a) Perfil do Sítio Toca do Sítio do Meio}

Do ponto de vista arqueológico, trata-se de um sítio pré-histórico, no qual todos os níveis foram ocupados, ou seja, toda a coluna estratigráfica é arqueológica, como indicam os vestígios encontrados e estudos anteriores, inclusive com geocronologia definida. O depósito que preenche o abrigo ocorreu em sequência de fluxo de detritos, com queda de blocos e novo fluxo depósito da base para o topo. Nele provavelmente ocorreu um momento de preparação da paisagem para receber o sedimento e, posteriormente, o momento de entulhamento. Não havendo mais energia suficiente para a retirada desses sedimentos, sugere-se que estes estejam preservados desde o último ciclo deposicional.

Neste sítio a camada constituída por fragmentos rochosos do arenito paleozóico separa duas unidades sedimentares cascalhosas. Provavelmente, este nível é fruto do desprendimento dos blocos fragmentados oriundos do teto do abrigo, recortado por fraturas, frequentes em rochas sedimentares bem litificadas.

A partir da observação de campo foi possível caracterizar o depósito sedimentar como uma cascalheira. No abrigo o carreamento de sedimentos, geralmente entre as diáclases e fraturas, formam rotas preferenciais, que vai condicionando o preenchimento das depressões e espaços de acomodação. Diferente da formação das rampas de colúvios, o preenchimento do espaço de acomodação na área estudada ocorreu por fluxos de lama canalizados e direcionados em função dos planos de maior declividade das fraturas, muito semelhante às situações encontradas em outros abrigos, também preenchidos pelos fluxos torrenciais.

Outra característica evidenciada neste sítio foi à constatação da ocorrência de queda de blocos (rock-fall). Tal fenômeno costuma ocorrer em surplombs, que são encostas negativas. Essas quedas de blocos estão associadas a mais de um episódio de desmoronamento. Desta forma, pode-se pensar em uma repetição de eventos, os de maior torrencialidade, associados à mud flows, corrida de lama, e momentos de queda de blocos.

Embora as quedas de blocos não estejam diretamente associadas à chuva, esta pode influenciar e desencadear o fenômeno. A umidificação dos planos acaba gerando um aumento de peso entre as fraturas de alívio de pressão, desencadeando a ruptura dos blocos. O abrigo apresenta muitas fraturas, subparalelas à superfície, características de alívio de pressão. Ao serem impregnadas de água tornam-se mais susceptíveis ao dinamismo gravitacional.

O topo do depósito analisado é marcado por uma cascalheira com matriz fina, suportado de blocos arredondados a extremamente angulosos, com arestas bem preservadas, indicando a incorporação de material que despencou na proximidade e também de material que sofreu transporte ou que incorporou sedimentos transportados por ocasião da formação da base geológica sedimentar. Observou-se 
o encaminhamento do páleo-fluxo canalizado proveniente dos dois lados da encosta, ambos convergindo para a depressão, trazendo muito material em suspensão.

O perfil (Figura 6) mostrou uma classificação textural, de acordo com Shepard (1954), predominantemente arenosa, mas com presença também de areia síltica. Conforme o diagrama de Pejrup (1988), em relação à energia hidrodinâmica atuante na deposição dos sedimentos, o resultado da análise foi coerente com a natureza granulométrica do depósito observada em campo, ou seja, energia de deposição de moderada a muito alta.
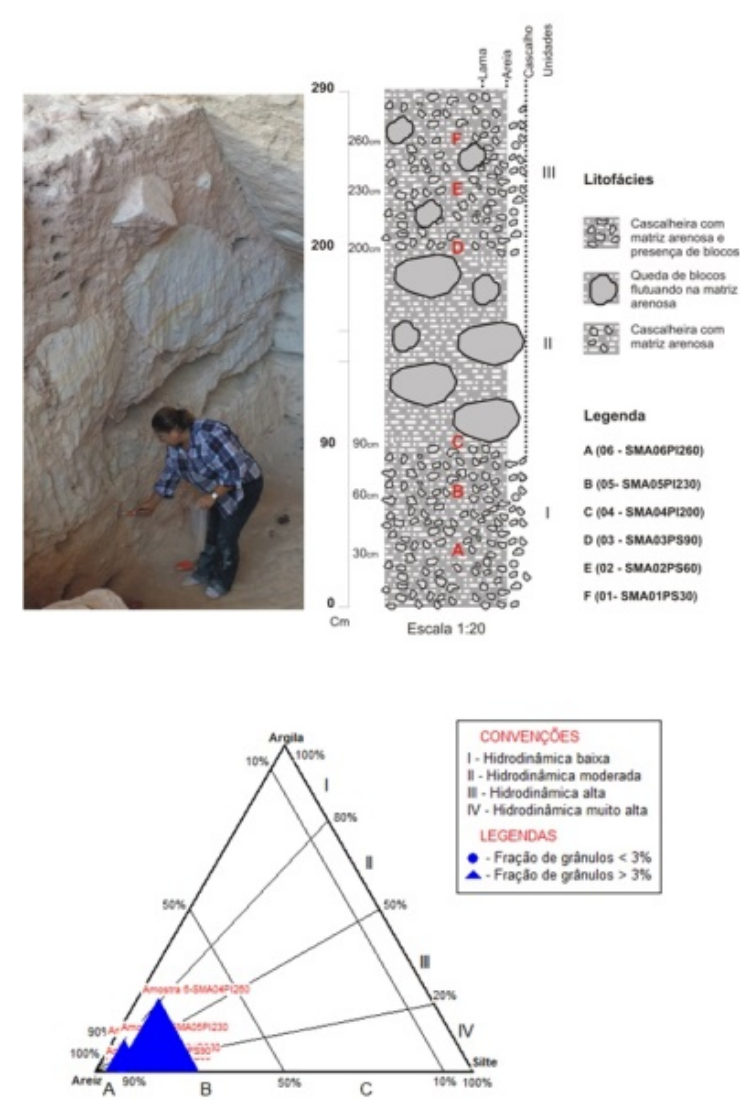
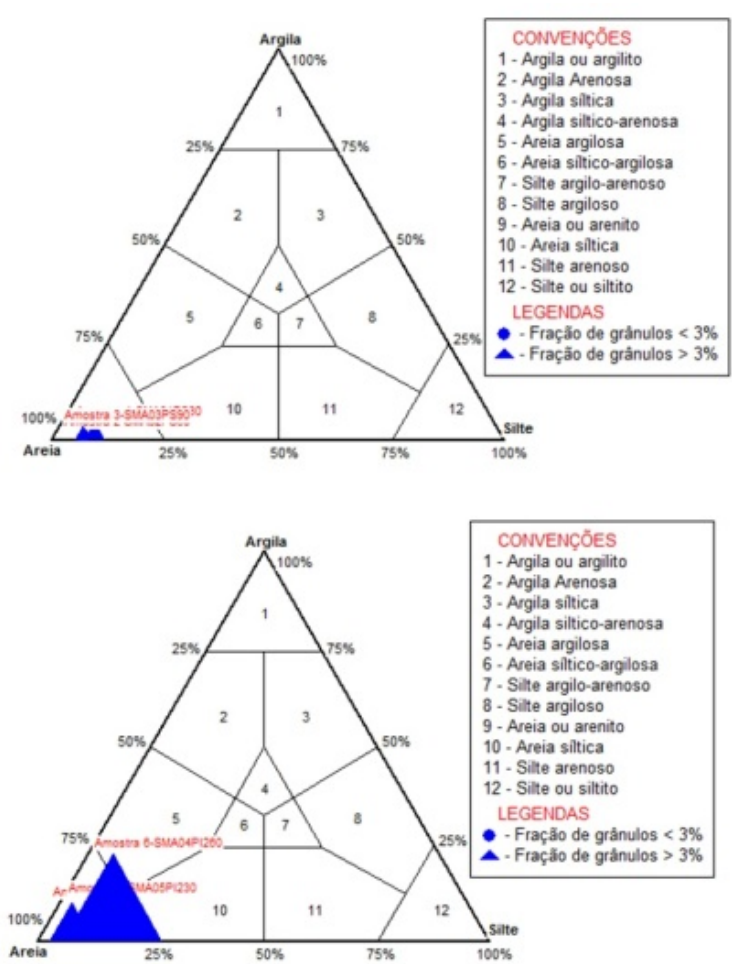

Figura 6: Perfil estratigráfico do Sítio do Meio, localizado na Bacia do Parnaíba, dentro no Parque Nacional Serra da Capivara.

Os sedimentos estão diretamente acomodados sobre as rochas paleozóicas areníticas, as camadas de cascalheira são intercaladas por um nível de concentração de matacões, calhaus e blocos de arenito. O resultado obtido a partir dos parâmetros de Folk e Ward (1975) demonstrou a predominância de areia média a grossa. A primeira camada é uma cascalheira sustentada por matriz, possui seixos e blocos de quartzo arredondados e blocos de arenito subangulares, com diâmetro médio em areia média, pobremente selecionada. Já a camada de cascalheira do topo exibe a parte grossa composta por seixos de quartzo, subarredondados a arredondados. A matriz é caracterizada como areia cascalhosa, com diâmetro médio de areia média a grossa, muito pobremente selecionada. 


\section{b) Perfil do Sítio da Toca do Gordo do Garrincho}

A Toca do Garrincho é um sítio de domínio cárstico bastante importante do ponto de vista da arqueologia e paleontologia. Foram encontrados em estratigrafia dois dentes humanos, associados aos animais fósseis sob o manto estalagmítico, datados pelo método radiocarbônico em $12.170 \pm 40$ anos AP, podendo também chegar a 15.245 até 14.690 AP, datação calibrada por 2 Sigma com resultado de $95 \%$ de probabilidade, segundo Felice (2006).

Os sedimentos encontrados nessas áreas são geralmente formados por fragmentos de rochas e minerais oriundos da decomposição química e desintegração física, transformados pela segregação granulométrica dada pelo transporte e pelos processos diagenéticos ocorridos posteriormente à sedimentação. No caso dos sedimentos do Garrincho sua morfologia adquire aspecto de rampas em avental de colúvio, preenchendo paleo-concavidades e depressões, invertendo no relevo local. Houve Eliminação de suas rugosidades possibilitando uma rampa de sedimentos que trunca em knickpoint bastante evidente a base da elevação calcária no domínio das rochas cristalinas da depressão periférica à Bacia sedimentar. A sedimentação dos colúvios se deu por alternância entre fluxos de detritos e corridas de lama. Estas muitas vezes podem ser responsáveis por transportar ossos de animais misturados para dentro da caverna (Felice, 2006).

A trincheira escolhida como ponto de coleta teve uma primeira campanha de escavação no ano de 2003, e está localizada próximo à entrada de uma caverna esculpida pelos processos cársicos no maciço calcário. A profundidade da escavação nos sedimentos próximos à borda do relevo em inselberg calcário possui uma profundidade de 2,35 m. Este depósito é formado por três litologias. A cascalheira ocorre em nível intermediário e no topo do afloramento. A camada intermediária tem $0,2 \mathrm{~m}$ e no topo $0,75 \mathrm{~m}$ de espessura. A camada de cascalheira é sustentada por matriz fina e constituída por seixos e raízes, seguida por uma camada stone line com fenoclastos angulosos e grossos. A base do perfil apresenta maior concentração de argila, demostrando clara transição entre a deposição de grossos e finos (Figura 7). Nesta trincheira não foi possível atingir o embasamento rochoso.

A formação desses depósitos reflete a remobilização dos mantos eluviais de intemperismo, recobertos por vegetação esparsa, dos serrotes de mármore. Indica também a contribuição dos sedimentos vindos da área da Bacia do Parnaíba. Eles foram evacuados por fluxos de detritos com alta viscosidade não canalizados, durante enxurradas, e fluxos de maior fluidez, do tipo corridas de lama, preenchendo tanto as porções inferiores da encosta quanto as antigas paleodepressões localizadas no seu sopé. Estas paleodepressões são os lapiás, conjunto de incisões formadas pela dissolução do mármore, frente à ação de fluxos de água corrente.

A análise granulométrica permitiu classificar o material como areia e areia síltica, segundo o diagrama de Shepard (1954). A classificação conforme o diagrama de Pejrup (1988) mostrou um ambiente com energia hidrodinâmica alta e muito alta. Esse dado mostra-se coerente com outras pesquisas desenvolvidas na região. 

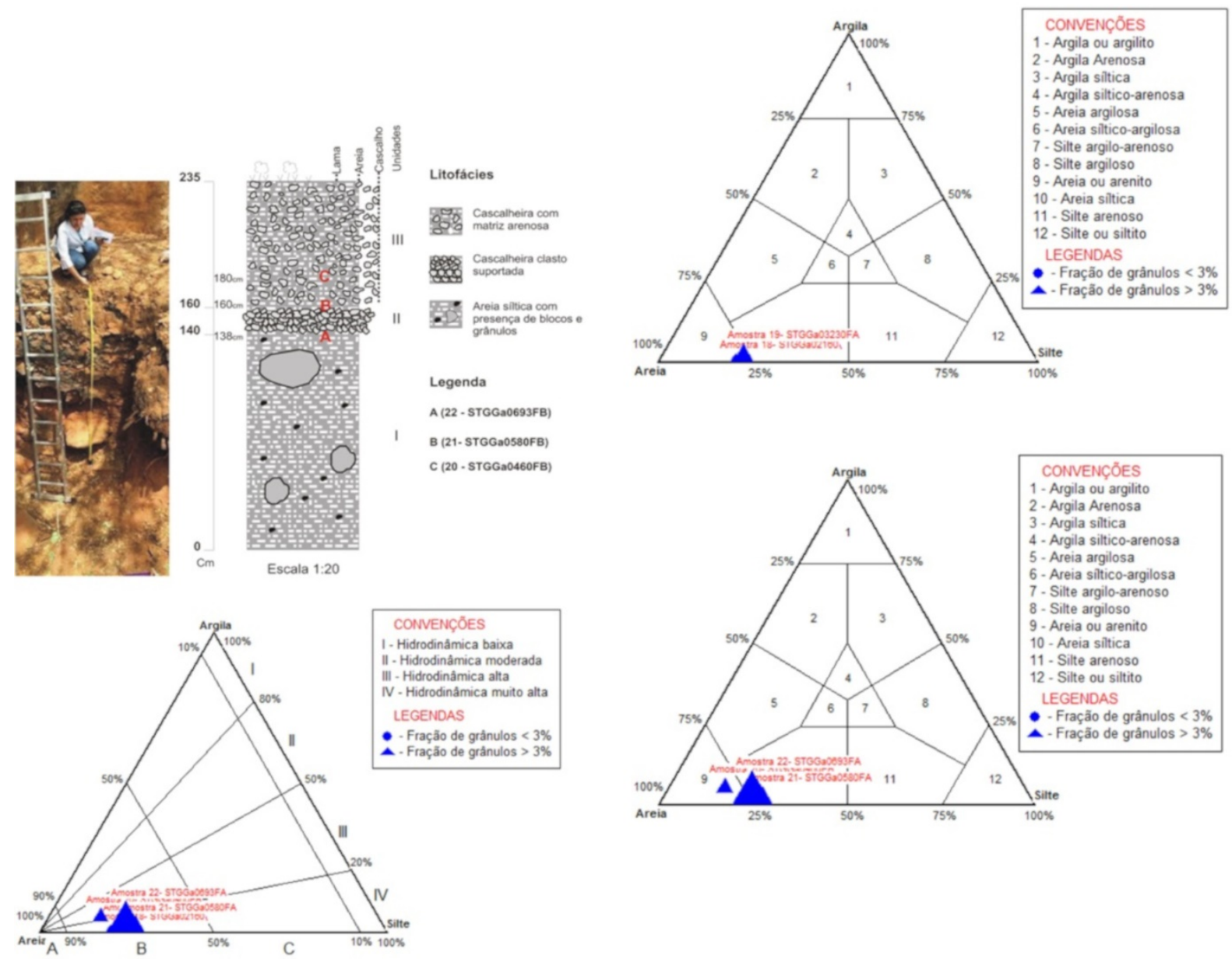

Figura 7: Perfil estratigráfico do Sítio Toca do Gordo do Garrincho.

As formações estruturais para o sítios de carste demonstram claramente a influência da ação das chuvas. A camada basal desse depósito apresenta tufos calcários intercalados com deposição de lama. Segundo Ford e Pedley (1996), tufo é um termo geral que designa uma grande variedade de sedimentos calcários, depositados em água doce, em ambientes continentais, comuns ao Quaternário superior e formados sob climas diversos, desde temperados até semiáridos. O tufo calcário é produto da precipitação do carbonato de cálcio, contendo baixo teor de magnésio, em temperatura ambiente.

A importância da presença de tufo no depósito reside no testemunho local de um clima oposto ao clima presente. Embora o clima semiárido já estivesse vigente, é possível afirmar que esse seria diferente do atual, com maior precipitação de chuvas e favorável à dissolução do calcário. Esses níveis de precipitação de carbonato pode ter sua formação associado também à maior disponibilidade de água nas cavernas. 


\subsection{Caracterização Composicional: Teste químicos e Instrumentais.}

\subsubsection{Caracterização Elementar por Fluorescência de Raio X por Dispersão de Energia (EDXRF).}

A análise elementar utilizando a Fluorescência de Raios $X$ para o estudo geoquímico dos sedimentos dos sítios Toca do Sítio do Meio e Toca do Gordo do Garrincho, possibilitou identificar os elementos e tecer as considerações que se apresentam de seguida.

O elemento de maior destaque na composição da fração sólida de ambos os grupos de amostras foi o Si. Esse elemento constitui mais da metade da composição de cada camada dos perfis estudados. Este dado foi observado a partir da análise granulométrica, sendo constatado na observação que as areias quartzosas representam o componente natural principal dos sedimentos dos sítios que estão localizados na Bacia Sedimentar do Parnaíba, como também foi observado para o sítio de carste localizado em domínios morfoestruturais da Depressão Periférica do São Francisco. A elevada porcentagem de areia na composição de ambos foi referendada também pelos ensaios de Difração de Raios $X$. Para a análise de Fluorescência de Raio $X$, foi considerado um limite de concentração elementar para efeito de análise significativa a partir de $50 \mathrm{ppm}(0,005 \%)$.

\section{- Toca do Sítio do Meio}

As concentrações de $\mathrm{P}$ para este sítio mostraram variação entre os níveis de deposição sedimentar e a rocha (controle), como também variação dos níveis entre si. Em relação aos níveis de sedimentação, sua associação pode estar na presença de $\mathrm{Al}, \mathrm{Fe}$ e $\mathrm{Ca}$, como também associado à ação antrópica. Para este sítio as evidências materiais dos registros arqueológicos já identificados (pinturas rupestres, material lítico, fogueiras estruturadas etc.) e datados vêm corroborar com as observações de campo e análises químicas aqui realizadas.

Embora a presença de fosfatos no solo seja afetada por vários fatores, como por exemplo, a origem geológica, a granulometria e a solubilidade, pelas características físicas e químicas (textura, mineralogia, capacidade de adsorção de ânions, $\mathrm{pH}$, teores de $\mathrm{Ca}, \mathrm{Mg}, \mathrm{P}, \mathrm{Fe}, \mathrm{Al}$, etc.), as concentrações de fosfatos $\left(\mathrm{PO}_{4}{ }^{-3}\right)$ tem demonstrado ser especialmente apropriado na caracterização de solos e sedimentos afetados pela ação humana.

A maior parte dos solos brasileiros é deficiente em fósforo, portanto de difícil extração. Podendo ser obtido naturalmente em pequenas concentrações, o $P$ possui uma forte interação com o substrato sólido. Assim, ao estudar o fósforo, é preciso reconhecer estas interações e compreender a dinâmica das formas disponíveis nesse solo.

De acordo com a literatura, os teores totais de fósforo em solos variam de pouco mais de zero em solos arenosos, até valores de 2000 a 3000 ppm ou mais $(0,2$ a $0,3 \%)$. Parte desse fósforo pode estar relacionada com a matéria orgânica, embora esse tipo de análise seja específico para cada região. Neste contexto, observando os valores 
encontrados é pertinente atestar o fósforo como constituinte também antrópico para o Sítio do Meio.

A presença do $\mathrm{K}$ diminui em todas as camadas a partir da rocha mãe, no entanto observou-se aumentos e diminuições em sequência nas camadas sotopostas ao embasamento. Tal comportamento, além de evidenciar a depleção real dessa base em relação ao material parental, também denota a origem alóctone das camadas sobrejacentes, indicando mais de um aporte coluvial de material previamente intemperizado oriundo de outras porções do abrigo, logo não necessariamente derivado in situ dentro da mesma sequência.

O Ti apresentou-se com maior teor nas amostras provenientes da rocha controle, exibindo pequenas variações entre os níveis do perfil. Esse elemento é considerado "imóvel", mas pode se movimentar como partícula coloidal como anatásio, mineral secundário formado pela precipitação do titânio (Taylon, Enggleton, 2001). Produtos residuais do intemperismo são agrupados comumente sob a forma de minerais resistentes. Além do quartzo, destacam-se outros minerais resistentes que ocorrem como componente traço na rocha de origem, mas que são concretados por depleção durante o processo de intemperismo. Os mais comuns são o zircão, ilmenita, anatásio, granada e magnetita, turmalina e monazita. Outros minerais podem ainda ser intemperizados em fases secundárias como a hematita, goethita e gibsita, que são mais estáveis em condições de alteração superficial, se mantendo também como minerais resistentes (Taylon, Enggleton, 2001).

O Fe possui maior concentração nas amostras de sedimento coluvial do que na rocha matriz. Este comportamento justifica-se pela enorme influencia da ação do intemperismo na formação desses depósitos levando à concentração percentual do ferro enquanto óxido e hidróxido na fração argila. Os elementos traço como o $\mathrm{Pb}, \mathrm{Nb}$, Y, Rb, Zn, Cu, V, Mn, Ni, Cr, Sn aparecem em todas as amostras inclusive na rocha controle, embora com diferentes proporções de variabilidade não expressiva na sequência.

Nos pontos amostrados do perfil para esse sítio, as maiores concentrações de elementos, após o $\mathrm{Si}$, são do $\mathrm{Al}$, seguido pelo Fe. Justifica-se esse fato pela ação do intemperismo tropical, no qual a perda de bases leva à concentração parcial dos elementos quimicamente mais imóveis. Além desses, em ordem decrescente de concentração, constata-se como significativa a presença de $\mathrm{K}, \mathrm{Ti}, \mathrm{P}, \mathrm{Ca}, \mathrm{Cl}$. Este grupo de cátions, juntamente com elementos que ocorrem em menor teor ( $\mathrm{Sr}, \mathrm{Zn}, \mathrm{Ag}$, $\mathrm{Zr}$ ), pode estar vinculado à presença de componentes orgânicos nos sedimentos, como também à mineralogia da rocha.

Quanto ao $\mathrm{Al}$, sua concentração também está relacionada à presença de aluminossilicatos na forma de argilominerais, sendo detectado em todos os níveis estudados dos sítios de origem sedimentar, podendo ser confirmado a partir da análise dos constituintes mineralógicos determinados pela difração de raio $\mathrm{X}$. 


\section{- Sítio Toca do Gordo do Garrincho}

A análise elementar de Fluorescência de raio X para o Sítio do Garrincho, apresentou altas concentrações do elemento cálcio (94,933\%), mostrando teores bem diferenciados para as amostras de rocha mãe do Sítio do Meio, coerente com o tipo de rocha do abrigo, caracterizada por ser um calcário metamorfizado com predominância de carbonato de cálcio, característica de rochas dos domínios morfoestruturais da Depressão Periférica do São Francisco contígua à borda da Bacia do Parnaíba. O magnésio apresentou concentrações significativas em relação aos sítios já estudados, mas com pequenas variações entre a rocha mãe e os níveis entre si, mostrando que o material é composto por camadas sucessivas e empilhadas, de origem alóctone, ou seja, não derivam diretamente do intemperismo in situ da rocha, mas constituem episódios individuais de coluvionamento.

Para o elemento Fe todas as amostras apresentam elevadas concentrações. Os teores obtidos para este sítio em relação aos obtidos para as amostras do Sítio do Meio foram os mais expressivos. Sendo evidenciado também valores elevados de Al, elemento este que não é comum ao tipo de rocha deste sítio, mas está presente devido ao processo de intemperização que resultou em sua concentração. Assim, esses valores elevados de $\mathrm{Fe}$ e $\mathrm{Al}$ são condizentes com o ambiente intempérico prevalente, sob condições tropicais e com presença de água no sistema.

Para o Sítio do Garrincho as concentrações de Fe, Si e Al são também as mais elevadas, seguidas por $\mathrm{Ca}, \mathrm{K}$ e P. As concentrações de potássio para a rocha controle são baixas, característica diferente do outro sítio discutido, enquanto que para as amostras de sedimento sua concentração é mais elevada e variando entre os níveis. Essa participação do $\mathrm{K}$ em concentrações mais elevadas que na rocha mãe aponta para a depleção de outros elementos e concentração do K possivelmente incorporado na fração argila neoformada, sob condições de semiaridez.

A proporção relativa dos compostos de fósforo, com ferro, alumínio e cálcio (e outros metais), em menores proporções, é condicionada também pelo $\mathrm{pH}$, e pelo tipo e quantidade de minerais existentes na fração argila. Em solos ácidos, com predomínio de caulinita e óxido de ferro e alumínio, são mais importantes as combinações de fósforo com ferro e alumínio, enquanto que em solos neutros ou calcários, aparecem mais fosfatos de cálcio, principalmente as apatitas, que são mais freqüentes em solos alcalinos, de ordem elevada e baixa solubilidade. Os horizontes entre 100 e $60 \mathrm{~cm}$ da superfície apresentam claramente teores mais elevados de $\mathrm{P}$, o que sugere serem esses os níveis com maior probabilidade de ocorrência de ocupação e de registro arqueológico.

Para o Sítio do Garrincho, situado sobre calcários metamórficos, constatou-se a ocorrência de um pH mais elevado, alcalino. Essa associação está efetivamente condicionada ao tipo de material do qual se originou o sedimento, uma vez que a rocha mãe apresenta grande teor de $\mathrm{Ca}$, que favorece a elevação do pH para alcalino. O titânio presente na rocha controle para este sítio possui pequena porcentagem $(0,205 \%)$, mas com a ação concentradora do intemperismo, seus teores nas amostras 
aumentaram percentualmente, embora apresentando pequenas variações entre os níveis amostrados.

Para melhor interpretação dos resultados de fósforo obtidos, considerando a concentração natural do elemento fósforo, de acordo com a literatura já citada, as concentrações encontradas evidenciam que todas as camadas dos perfis estudados indicam algum nível de perturbação antrópica. É importante ressaltar que a associação destes não reflete uma escala de valores universais, mas em dados proporcionais obtidos para uma determinada região. Assim os valores podem sofrer variações devido à quantidade das amostras e podem não ser compatíveis com os de outras regiões. Existem fatores que podem influenciar nos teores de fósforo no solo, como por exemplo, fatores climáticos, vegetacionais, como também características da rocha mãe e fatores relacionados com as formas culturais de uso da terra.

\subsection{Caracterização Mineralógica por Difração de Raio $X$}

A composição mineralógica da fração argila é uma propriedade significativa na caracterização de níveis arqueológicos. Essa análise pode fornecer informações relativas aos processos intempéricos e pedogenéticos atuantes no local, além daqueles derivados da influência antrópica na adição ou alteração dos componentes.

\section{- Sítio Toca do Sítio do Meio}

Os difratogramas obtidos a partir da análise da fração argila para este sítio mostraram seus principais constituintes como argilominerias. Para a rocha mãe identificou-se minerais de quartzo, caulinita e coesita. Para o conjunto de amostras do perfil foi possível identificar além da ocorrência de quartzo, caulinita, secundariamente montmorillonita e formação de complexos metálicos de Fe e Al na forma de hidróxidos, em sua grande maioria associados ao $\mathrm{P}$ e Ti. A partir desse resultado é possível reafirmar as observações feitas anteriormente sobre os constituintes composicionais dos depósitos sedimentares aqui estudados. São constituintes de origem alóctone, fruto de processos intempéricos influenciados por fatores pedogenéticos, climáticos e antrópicos durante o processo de ocupação humana pré-histórica. No entanto, no caso dos depósitos derivados dos sedimentos siliciclásticos paleozoicos da bacia do Parnaíba, constata-se a depleção relativa em bases trocáveis, o que inibe a formação das esmectitas mesmo em face do ambiente semiárido.

\section{- Sítio do Gordo do Garrincho}

No caso do Sitio do Garrincho verifica-se um comportamento semelhante ao do outro sítio sobre litologia calcária, atestando a forte presença da água no momento de evolução dos mantos de intemperismo que resultaram nos colúvios que ora preenchem os espaços de acomodação que balizam o inselberg. Os argilo minerais foram predominantemente a caulinita, os fosfatos e secundariamente a montmorillonita com substituição das bases trocáveis pelo $\mathrm{Al}$, indicando perda por lixiviação. 
4.4. Espectroscopia de Absorção Molecular no Ultravioleta/Visível (UV-visível) e Infravermellho com Transformada de Fourier (FTIR).

Os resultados obtidos nas técnicas instrumentais por espectroscopia de Absorção Molecular no Ultravioleta/Visível (UV-visível) e Infravermellho com Transformada de Fourier (FTIR) foram:

\section{a) Ultravioleta/Visível (UV-visível)}

O conjunto de amostras do Sítio do Meio e Sítio do Garrincho analisadas pela técnica de espectroscopia de absorção molecular no Ultravioleta-Visível (UV-visível) foi utilizado com a finalidade de identificar a presença de constituintes do fósforo nos sedimentos arqueológicos.

Os espectros apresentaram na região do visível $\left(400-800 \mathrm{~cm}^{-1}\right)$ um decréscimo linear na absorção com a diminuição do comprimento de onda. A absorção máxima para todas as amostras de sedimento ocorreu na faixa de 600 a $660 \mathrm{~cm}^{-1}$, faixa de absorção característica para a identificação do fósforo. A técnica de UV-vis utilizada para determinar a presença de fósforo mostrou-se como ferramenta complementar à análise de DRX e FRX na determinação de constituinte fosfático.

b) Infravermellho com Transformada de Fourier (FTIR).

Os espectros na faixa do Infravermelho permitem identificar diferentes ligações químicas entre átomos pelas deformações rotacionais e vibracionais, as quais absorvem energia em determinada frequência de ressonância de acordo com as características químicas dos átomos envolvidos. A aplicação dessa técnica para a análise das amostras de sedimentos dos sítios estudados possibilitou a identificação dos grupos funcionais que identificam os minerais como a caulinita, montmorillonita, óxido de silício.

\subsection{Determinação Físico-Química: cátions trocáveis, matéria orgânica e medidas de} $\mathrm{pH}$.

De acordo com as análises químicas dos sedimentos, as amostras apresentaram teores elementares variáveis, e essas variações obtidas nas concentrações podem estar relacionadas tanto com a geologia como com as condições das atividades antrópicas. Algumas amostras apresentaram concentrações elevadas, não só para fósforo, mas também para $\mathrm{Ca}, \mathrm{Mg}, \mathrm{K}, \mathrm{Na}$, $\mathrm{Al}$ e matéria orgânica. Já outras forneceram concentrações bem inferiores.

Em geral os solos das regiões tropicais são carentes em relação a alguns elementos, como por exemplo, o $\mathrm{K}$ e $\mathrm{P}$. As diferentes forças com que o $\mathrm{K}$ se adsorveu aos minerais secundários do solo permitem classificá-lo quimicamente em não-trocável, trocável e solúvel em $\mathrm{H}_{2} \mathrm{O}$. O trocável é o mais utilizado no estudo da fertilidade do solo. O não trocável está presente no solo em micas e feldspatos, minerais primários com altas concentrações de K, que está firmemente retido, e só é disponível quando os minerais se decompõem. Por outro lado a concentração do K solúvel é baixa, mas altamente móvel. 
Existe pouco interesse na determinação de $\mathrm{K}$ devido ao seu caráter dinâmico. As concentrações mais elevadas de $\mathrm{K}$ são encontradas em solos salinos, em média de 9,6 mM/L. Em solos ácidos valores de 0,7 mM/L são encontrados. Os solos com boa capacidade de retenção de água, bem tamponados possuem bons teores de $\mathrm{K}$. Em alguns solos, os minerais de argila fixam potássio, particularmente quando altas doses de calcário estão presentes, o que altera o pH.

Mas observou-se nos resultados, que algumas amostras do Sítio do Meio, possuem $\mathrm{pH}$ mais baixos, são ácidos, e apresentaram as mais baixas concentrações de $\mathrm{K}$. A associação de constituintes como o Fe e o Al também podem ocorrer, o que justificaria essa alteração. As mais altas concentrações de $\mathrm{K}$ estão relacionados ás amostras com pH mais elevados, porém neutros entre 6,99 a 7,09. Complexos argilosos com $\mathrm{pH}$ ácidos em função da presença do alumínio podem ligar-se ao $\mathrm{K}$ em ambientes com maior disponibilidade de $\mathrm{Fe} \mathrm{e} \mathrm{Al,} \mathrm{como} \mathrm{é} \mathrm{o} \mathrm{caso} \mathrm{das} \mathrm{amostras} \mathrm{de} \mathrm{sedimentos}$ analisadas.

Nas amostras que apresentam também altas concentrações de K e matéria orgânica associada, para esse grupo, observa-se que as concentrações de Ca e Mg estão diretamente associadas aos teores de $\mathrm{K} \mathrm{e} \mathrm{pH.} \mathrm{O} \mathrm{pH}$ mais elevado favorece a maior capacidade de troca catiônica.

A maior parte de cálcio e magnésio provém dos minerais do solo, absorvem eletrostaticamente em forma trocável, evitando perdas por lavagem. O Ca e Mg são adsorvidos pelos colóides ou encontram-se na solução do solo como catiônicos. Os solos arenosos pobres em argila e húmus são deficientes em Ca e Mg.

Quanto às concentrações de matéria orgânica, foram observadas elevadas concentrações em três amostras do Sítio do Meio e em três do Sítio do Garrincho. O alto teor nas amostras sugere um maior poder tampão, evitando a mudança brusca do $\mathrm{pH}$. Solos arenosos possuem menos poder tampão, que as argilas.

É relevante dizer que a determinação dos elementos $\mathrm{K}, \mathrm{Na}, \mathrm{Ca}, \mathrm{Mg}$ e Al tiveram uma importância secundária em relação a determinação do $P$, porém são de grande ajuda, pois esses cátions estão intimamente relacionados a acidez encontrada no solo. E esse baixo $\mathrm{pH}$ não permitiu a conservação de ossos humanos em idades mais antigas (Moraes, 2004).

Para esse ensaio os valores de fósforo mostram pouca variação, o P aqui apresentado trata-se do fósforo considerado assimilável. As amostras que foram coletadas em pontos diferentes, mas em um mesmo nível arqueológico, apresentaram teores elementares diferentes, sobretudo de P. Observou-se que as concentrações mais elevadas foram determinadas nas amostras coletadas próximas aos locais onde foram encontrados vestígios.

As análises feitas para o fósforo também no espectrofotômetro com comprimento de onda de $660 \mathrm{~nm}$ possibilitaram reafirmar a presença do fósforo nas amostras analisadas no fotocolorímetro. Os resultados obtidos evidenciaram teores de fósforo com concentrações elevadas e com maior precisão e menor desvio padrão $(0,0006)$. 
Essa técnica foi eficiente como ferramenta para o estudo laboratorial do fósforo em sedimentos arqueológicos, e mais uma vez reafirma o fósforo como indicador da presença do homem nesses solos. O teor de fósforo depende também da sua máxima fixação no solo, pH ótimo entre 4 e 5 (Bearat \& Dufournier, 1994).

\section{Conclusão}

A análise geomorfológica e geoquímica de sedimentos arqueológicos de sítios estudados permitiu evidenciar que apesar do material parental, a rocha mãe, não conter em quase nenhuma das amostras o elemento fósforo $(P)$, ele está presente praticamente em todos os depósitos quaternários da área, indicando que houve um input externo (input alóctone), o que é um forte indício da existência de níveis de ocupação humana pré-histórica. A associação climática que se faz entre argilominerais e sedimentos deve ser um pouco mais cautelosa, pois observa-se que há um controle muito grande da rocha, como no caso dos depósitos oriundos da Bacia Sedimentar, que são muito pobres em elementos trocáveis, em bases, e praticamente só resultam em quartzo e caulinita. Embora a presença alóctone do fosfato também gere hidroxiapatita ou ferro hidroxidoapatita, em algumas situações, enquanto que nos sítios localizados no calcário (na depressão) sobre as rochas da Faixa de Dobramentos do Riacho do Pontal, ao contrário do que se poderia esperar, a presença do cálcio ( $\mathrm{Ca}$ ) não levou à formação de argila 2:1, esmectitas, mas sim reforça a presença das caulinitas. E secundariamente ocorre a presença de compostos que contêm ferro, indicando que o clima de deposição desses minerais foi em um clima provavelmente mais úmido, ou mesmo que o manto de intemperismo de que esses sedimentos provieram se desenvolveu sob condições de lixiviação, de perda de bases, e, portanto tais bases não ficaram guardadas sob forma de argilominerais. $\mathrm{Na}$ caracterização de perfis arqueológicos, torna-se fundamental interpretar o significado do impacto físico-químico da presença de certos marcadores nas sequências sedimentares de controle (induzidos pela ação humana no local), aferindo seus significados ambientais (geomorfológico, pedológico, vegetacional dentre outros). Os sedimentos assim formados são de valor essencial para interpretar os processos culturais. Quanto à aplicação metodológica dos marcadores geoquímicos, a níveis estratigráficos previamente escolhidos, é possível recompor a dinâmica e evolução ambiental das paleopaisagens. Conclui-se ainda que os métodos de análises química utilizados no estudo, apesar de possuírem algumas limitações, como o desconhecimento de determinadas práticas culturais (que modificam de forma direta a concentração de fosfatos), demonstraram resultados condizentes com a pesquisa arqueológica. Observou-se uma grande concentração fosfática nos perfis que correspondem justamente aos níveis de maior concentração de material arqueológico, isso reforça a tese de que este estudo é perfeitamente aplicável à indicação de ocupação, além de poder auxiliar também na determinação das áreas de maior atividade humana. 


\section{Agradecimentos}

Agradecemos à Universidade Estadual do Piauí-UESPI por sua contribuição com o transporte para a execução de todos os campos para coleta de amostras, como também por ter cedido sua estrutura física laboratorial para o desenvolvimento deste trabalho. Agradecemos ainda à Fundação Museu do Homem Americano (FUMDHAM), na pessoa da Dra. Niéde Guidon, por ter permitido o desenvolvimento deste projeto nos sítios arqueológicos que fazem parte do Parque Nacional Serra da Capivara e pelo incentivo à pesquisa.

\section{Bibliografia}

Almeida, F. F. M., Hasui, Y., Brito Neves, B. B., Fuck, R. A. (1977). Províncias Estruturais Brasileiras. In: Atas do VIII Simpósio de Geologia do Nordeste. (pp. 363-391).

Angelucci, D. E. (2010). The recognition and description of Knapped lithic artifacts in Thin section. Geoarchaeology: an International Journal, 25(2), 220-232. https://doi.org/10.1002/gea.20303

Angelucci, D. E., de Deus, M. (2006). Geomorfologia e ocupação pré-histórica no baixo curso do rio Sor: primeiras observações geoarqueológicas. Revista portuguesa de arqueologia, 9(2), 5-26. https://dialnet.unirioja.es/servlet/articulo?codigo=2090258

Angelucci, D. E., Zilhão, J. (2009). Stratigraphy and formation processes of the latepleistocene deposit at Gruta da Oliveira, Almonda Karstic System, Torres Novas Portugal. Geoarchaeology: an International Journal, 24(3), 277-310. https://doi.org/10.1002/gea.20267

Angelucci, D. E., Anesin, D., Susini, D., Villaverde, V., Zapata, J., Zilhão, J. (2013). Formation processes at a high resolution Middle Paleolithic site: Cueva Antón (Murcia, Spain). Quaternary International, 315, 24-41. https://doi.org/10.1016/j.quaint.2013.03.014

Angelucci, D. E., Anesin, D., Susini, D., Villaverde, V., Zapata, J., Zilhão, J. (2018). A tale of two gorges: Late Quaternary site formation and surface dynamics in the Mula basin (Murcia Spain). Quaternary International, 485, 4-22. https://doi.org/10.1016/i.quaint.2017.04.006

Angelucci, D. E., Peresani, M. (2001). The sedimentary sequence of Riparo Dalmeri (Grigno Valsugana, TN): pedostratigraphic and micromorphological features. Preistoria Alpina, 34, 155-162.

Alves, T. L., Brito, M. A. M. L. de, Lage, M. C. S. M., Cavalcante, L. C. D., Fabris, J. D. (2011). Pigmentos de Pinturas Rupestres Pré-históricas do Sítio Letreiro do Quinto, Pedro II, Piauí, Brasil. Química Nova, 181-185. http://quimicanova.sbq.org.br/detalhe artigo.asp?id=4405

Arruda, M. B. (1993). Ecologia e antropismo na área do município de São Raimundo Nonato e Parque Nacional Serra da Capivara (PI). Tese de Mestrado. Brasília: Instituto de Ciências Biológicas - Departamento de Ecologia - UNB - Brasília (DF).

Baggio Filho H., Freitas, M de O., Meneses, T. S. de., Costa, T. M. da (2012). Aspectos Geoarqueológicos do Sítio Cemitério Caixa d'Água: Vale do são Francisco - Minas Gerais/Brasil. Gnomos, 20(1), 42-48. https://doi.org/10.18285/geonomos.v20i1.26 
Beach, T., Dunning, N., Luzzadder-Beach, S., Cook, D. E., Lohse, J. (2006). Impacts of the ancient Maya on soil and erosion in the central Maya Lowlands. Catena, 65(2), 166-178. https://doi.org/10.1016/j.catena.2005.11.007

Bearat, H., Dufournier, D. (1994). Quelques experiences sur la fixation du phosphore par les ceramiques. Revue d'archéométrie, 18, 65-73.

Carter, G. F., Sokoloff, V. P. (1952). A study of soils and Land Forms of the Chesapeake Bay Margins. Soil Sciense, 74(2), 176.

Cavalcante, L. C. D. (2009). Arqueometria aplicada ao estudo de pigmentos, depósitos de alteração e paleossedimentos do Piauí. Clio Arqueologia, 24(1), 119-146. https://www3.ufpe.br/clioarg/images/documentos/V24N1-2009/2009v24n1a6.pdf

Cavalcante, L. C. D., Lage, M. C. S. M. (2010). Fósforo Inorgânico, fósforo orgânico e fósforo total como indicadores de ocupação humana pré-historica: otimização e validação de metodologia em paleossedimentos. Clio Arqueologia, 25(2), 11-36. https://www3.ufpe.br/clioarg/images/documentos/V25N2-2010/2010v25n2a1.pdf

CPRM - Companhia de Pesquisa de Recursos Minerais (2009). Projeto Borda da Bacia Sedimentar do Parnaíba. Teresina: Serviço Geológico do Brasil. Geoparque Serra da Capivara-PI. Proposta.

da Costa Honorato, L. (2009). Arqueologia da paisagem e geoarqueologia: experiências em projetos de pesquisa. Revista Tópos, 3(1), 127-147. http://revista.fct.unesp.br/index.php/topos/article/view/2226

Eidt, R. C. (1977). Detection and examination of anthrosols by phosphate analysis. Science, 197, 1327-1333. https://doi.org/10.1126/science.197.4311.1327.

Farias, W. M. (2012). Processos Evolutivos de Intemperismo Químico e Sua Ação no Comportamento Hidromecânico de Solos do Planalto Central. Tese de Doutorado, Publicação G.TD-077A/2012, Departamento de Engenharia Civil e Ambiental, Universidade de Brasília, Brasília, Distrito Federal.

Felice, G. D. (2006). Contribuição para estudos geoarqueológicos e paleoambientais: proposta metodológica (estudo de caso: Maciço Calcário do Garrincho, Piauí, Brasil). Tese de Doutorado, Universidade Federal de Pernambuco, CFCH, História, Recife.

Folk, R. L., Ward, W. (1957). Brazos River bar: a study in the significance of grain size

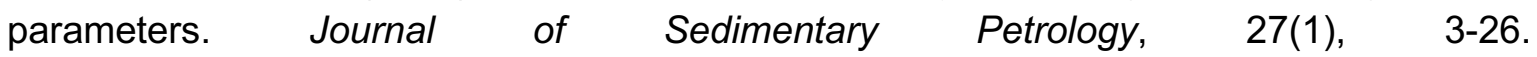
https://doi.org/10.1306/74D70646-2B21-11D7-8648000102C1865D

Ford, T. D., Pedley, H. M. (1996). A review of tufa and travertine deposits of the world. EarthScience Reviews, 41(3),117-175. https://doi.org/10.1016/S0012-8252(96)00030-X

Goes, A. M., Feijó, F. (1994). A Bacia do Parnaíba. Boletim de Geociências da Petrobrás, 8, 57-67.

Guidon, N., Peyre, E., Guérin, C., Coppens, Y. (2000). Resultados da datação de dentes humanos da Toca do Garrincho, Piauí-Brasil. Clio Arqueológica, 14, 75-83. https://www3.ufpe.br/clioarq/images/documentos/2000-N14/2000a5.pdf

Guidon, N., Pessis, A.-M., Parenti, F., Guérin, C., Peyre, E., Santos, G. M. (2002). Pedra Furada, Brazil: Paleoindians, Paintings and Paradoxes. Athena Review, 3(2), 42-52. 
Guérin, C. (1991). La faune de vertébrés du Pléistocène supérieur de l' aire archéologiquede São Raimundo Nonato (Piauí, Brésil). C. R. Acad. Sci. Paris, 312(sér. II), 567-572.

Guérin, C. (1993). La faune pléistocène de la Lagoa da Pedra à Conceição das Creoulas/Salgueiro, Pernambouc, Brésil. Clio Arqueológica, 1(9), 15-20. https://www3.ufpe.br/clioarq/images/documentos/1993-N9/1993a2.pdf

Holliday, V. T. (2004). Soils in Archaeological Research. Oxford University Press, Oxford.

Lage, M. C. S. M. (1996). Análise química de pigmentos de arte rupestre do sudeste do Piauí. Revista de Geologia, 9, 83-96. https://doi.org/10.11606/issn.25945939.revmaesupl.1997.113443

Lage, M. C. S. M., Fabris, J. D., Moraes, C. B., Cavalcante, L. C. D. (2006). Análise Química de sedimentos como indicador de ocupação humana pré-histórica no Parque Nacional Serra da Capivara. Clio Arqueologia, 20, 103-122. https://www3.ufpe.br/clioarg/images/documentos/2006-V1N20/2006v1n20a5.pdf

Lage, M. C. S. M., Cavalcante, L. C. D., Santos, J. de S. (2007). Estudo Químico de Sedimentos Arqueológicos do Parque Nacional Serra da Capivara, Piauí- Brasil. Fumdhamentos, VI, 106-114.

Manzanilla, L., Barba, L. (1994). La Arqueologia: Una Visión Científica del Pasado del Hombre. La ciência/123 para todos. Calzada de San Lorenzo-México.

Marwick, B. (2005). Element concentrations and magnetic susceptibility of anthrosols: Indicators of prehistoric human occupation in the inland Pilbara, western Australia. Journal of Archaeological Science, 32(9), 1357-1368. https://doi.org/10.1016/j.jas.2005.03.009

Melo, R. F. T., Gomes da Silva, D., Barros Corrêa, A. C. (2012). Avaliação da Dinâmica Geomorfológica do Município de Afrânio (PE), com Base na Abordagem Morfoestratigráfica. In: Anais do $9^{\circ}$ Simpósio Nacional de Geomorfologia. Rio de Janeiro.

Moraes, C. B. (2004). A Utilização da química como indicador de uma ocupação humana préhistórica no PARNA Serra da Capivara. Dissertação de Mestrado, Universidade Federal do Piauí, Teresina.

Moraes, B. C., Lage, M. C. S. M. (2003). Utilização da Química como Indicador de uma Ocupação Humana Pré-histórica no PARNA Serra da Capivara. A química torna sua vida melhor. In: Anais da $26^{\circ}$ Reunião Anual da Sociedade Brasileira de Química-SBQ, Poços de Caldas-MG.

Moraes, B. C., Lage, M. C. S. M., Gonçalves, N. T., Cavalcante, L. C. D., Hugon, P. (2004). Avaliação química de camadas estratigráficas do Sítio Toca do Boqueirão da Pedra Furada (BPF), PARNA Serra da Capivara. Livro de resumos do XXVI Congreso Latinoamericano de Química/27ª Reunião Anual da Sociedade Brasileira de Química, Salvador-BA, 2004.

Moraes, B. C., Corrêa, A. C. de B., Lage, M. C. S. M. (2013) Fundamentos da Geoarqueologia e Geoquímica na Indicação de Níveis de Ocupação Humana pré-histórica no Parque Nacional Serra da Capivara- Piauí, Brasil. In: ABEQUA, XIV Congresso da Associação Brasileira do Quaternário: Processos Naturais e Antrópicos. Um desafio para o desenvolvimento Sustentável. Natal, Rio Grande do Norte, Brasil. Associação Brasileira de Estudos do Quaternário. Disponível em: http://www.abequa.org.br/trabalhos/arq 2014 06.pdf 
Mutzenberg, D. da S., Correa, A. C. de B., Tavares B. de A. C., Cisneiros, D. (2015). Serra da Capivara National Park: Ruinform Landscapes on The Parnaiba Cuesta. In: Vieira B., Salgado A., Santos L. (eds) Landscapes and Landforms of Brazil. (pp. 253-263). World Geomorphological Landscapes. Springer, Dordrecht. https://doi.org/10.1007/978-94-0178023-0 23

Parenti, F. (1993). Le gisementpréhistoriquedupléistocènesupérieur de Pedra Furada (Piauí, Bresil) danslecontexte de lapréhistoireaméricaine. Fouilles, stratigraphie, chronologus, évolutionculturelle. PhD diss., École des Hautes Études en sciences sociales, Paris.

Parnell, J. J., Terry, R. E., Sheets, P. (2002). Soil chemical analysis of ancien activities in Cerén, El Salvador: A case study of a rapidly abandoned site. Latin American Antiquity. 13(3), 331-342.

Pejrup, M. (1988). The triangular diagram used for classification of estuarine sediments: a new approach. In: Boer, P. L., Van gelder, A., Nio, D. D. (eds.). Tide-Influenced Sedimentary Environments and Facies. (pp. 289-300). Reidel: Dordrecht.

Peyre, E. (1993). Nouvelle découverte d' un Homme préhistorique américainune femme de 9 700 ans au Brésil. C. R. Acad. Sci. Paris, 316(série II), 839-842.

Proudfoot, B. (1976). The analysis and interpretation of soil phosphorous un archaeological contexts. D. A. Davidson \& M. L. Shackley (eds.) Geoarchaeology: Earth science and the past. (pp. 93-113). Duckworth, London.

Salvia, E. S. La (2006). A reconstituição da paisagem da paleo-micro Bacia do Antonião e a sua ocupação pelo homem no pleistoceno. Tese de Doutorado, Programa de PósGraduação em História, Universidade Federal de Pernambuco, Recife.

Santos, J. C. dos (2007). O Quaternário do Parque Nacional Serra da Capivara, Piauí, Brasil: morfostratigrafia, sedimentologia, geocronologia e paleoambientes. Tese de Doutorado, Universidade Federal de Pernambuco, CTG. Recife.

Suguio, K. (1998). Dicionário de geologia sedimentar e áreas afins. Rio de Janeiro: Bertrand Brasil, 1.

Schlezinger, D. R., Howes, B. L. (2000). Organic phosphorus and elemental ratios as indicators of prehistoric human occupation. Journal of Archaeological Science, 27(6), 479492. https://doi.org/10.1006/jasc.1999.0464

Shahack-gross, R., Berna, F., Karlanas, P., Weiner, S. (2004). Bat guano and preservation of archeological remains in cave sites. Journal of Archaeological Science, 31(9), 1259-1272. https://doi.org/10.1016/j.jas.2004.02.004

Shepard, F. P. (1954). Nomenclature based on sand-sil-clay ratins. Journal of Sedimentary Petrology, 24(3), 151-158.

Taylor,G., Eggleton, R. A. (2001). Regolith geology and geomorphology. Wiley- Blackwell, 1 ed.

Torres, F. T. P., Marques Neto, R., Menezes, S. de O. (2012). Introdução à geomorfologia. São Paulo: Cengage Learning (Coleção textos básicos de geografia).

Trompette, R., Uhlein, A., Egydio-silva, M., Karmann, I. (1992). The brasiliano São Francisco Cráton revisited (Central Brazil). J. South Am. Earth Sciences, 6(1/2), 49-57. https://doi.org/10.1016/0895-9811(92)90016-R 
Villagran, X. S. (2010). Estratigrafias que falam: geoarqueologia de um sambaqui monumental. São Paulo: Annablume.

Villagran, X. S., Schaefer, C. E. G. R. (2011). Geoarqueologia das primeiras ocupações humanas na Antártica. Vestígios - Revista Latino-Americana de Arqueologia Histórica, 5(2), 117-136. https://doi.org/10.31239/vtg.v5i2.10653

Wilson, C. A., Davidson, D. A., Cresser, M. S. (2008). Multi-element soil analysis: an assessment of its potencial as an aid to arqueological interpretation. Journal of Archaeological Science, 35(2), 412-424. https://doi.org/10.1016/j.jas.2007.04.006

Artigo recebido em/ Received on: 16/11/2019

Artigo aceite para publicação em/ Accepted for publication on: 30/12/2019 